\title{
Two-dimensional organic-inorganic hybrid perovskite: from material properties to device applications
}

\author{
Shuang $\mathrm{Ma}^{1}$, Molang Cai ${ }^{2}$, Tai Cheng ${ }^{1}$, Xihong Ding ${ }^{1}$, Xiaoqiang Shi ${ }^{1}$, Ahmed Alsaedi ${ }^{4}$, \\ Tasawar Hayat ${ }^{3,4}$, Yong Ding ${ }^{1^{*}}$, Zhan'ao Tan $^{1^{*}}$ and Songyuan Dai ${ }^{1,4^{*}}$
}

\begin{abstract}
The two-dimensional (2D) perovskite (including pure-2D and quasi-2D) is formed by introducing large-group ammonium halides into conventional bulk perovskite. In the past twenty years, 2D perovskite materials were widely developed with the enriched species and advanced physicalknowledge in material characteristics as well as optoelectronic device applications. To review achievments in $2 \mathrm{D}$ perovskite, the fundamental mechanism and properties of $2 \mathrm{D}$ perovskite are introduced to offer insight into device performance. Moreover, the preparation methods of $2 \mathrm{D}$ perovskite films are summarized and compared. The latest successful applications of the 2D perovskite in the solar cells and light-emitting diodes fields, especially the advanced stability of $2 \mathrm{D}$ perovskite solar cells (PeSCs) and the efficient 2D perovskite lightemitting diodes (PeLEDs), are also achieved. Furthermore, the challenges and outlook of $2 \mathrm{D}$ perovskite materials are proposed.
\end{abstract}

Keywords: 2D perovskite, material properties, preparation methods, optoelectronic applications.

\section{INTRODUCTION}

Organic-inorganic hybrid perovskites

Since 2009, organic-inorganic hybrid perovskites have drawn great attention for the optoelectronic application. The structure and physical properties of these unique materials were first established by Weber in 1978 [1,2]. The general formula of perovskite is $\mathrm{AMX}_{3}$, where $\mathrm{A}$ stands for organic cations such as $\mathrm{CH}_{3} \mathrm{NH}_{3}{ }^{+}$or
$\mathrm{CH}\left(\mathrm{NH}_{2}\right)_{2}{ }^{+} ; \mathrm{M}$ for metal cations such as $\mathrm{Pb}^{2+}$ or $\mathrm{Sn}^{2+}$ $[3,4]$; and $\mathrm{X}$ for halide anions such as $\mathrm{Cl}^{-}, \mathrm{Br}^{-}$or $\mathrm{I}^{-}$, as shown in Fig. 1a, b. In recent years, 3D organometal halide perovskites have been widely applied to optoelectronic fields owing to excellent electrical and optical properties such as high carrier mobility, strong and widerange light absorption.

However, the crystal-lattice of bulk $3 \mathrm{D}$ perovskite is easy to be damaged when exposed to ultraviolet irradiation, high temperature and the hydrous environment, which accelerates the decomposition of perovskite into reactants and results in a rapid degradation of the device performance. Humidity is the most crucial factor for the device stability. Thus, strict synthetic conditions are required for the fabrication of high-quality perovskite films, and the perovskite devices exhibit poor long-term stability in the ambient environment. The bulk perovskite has small binding energies (for example, the binding energies of $\mathrm{MAPbX}_{3}(\mathrm{X}=\mathrm{Cl}, \mathrm{Br}, \mathrm{I})$ range from 20 to $50 \mathrm{meV}$ [5]), which blocks the formation of bound excitons, finally resulting in inefficient radiative recombination and low PL quantum efficiencies (PLQE) of thin films. Notably, the $\mathrm{MAPbI}_{3}$ structure even shows weak excitonic feature because of the low binding energy of $\sim 20 \mathrm{meV}$.

\section{D organic-inorganic hybrid perovskites}

$2 \mathrm{D}$ perovskite is developed as one of the alternatives with considerable moisture and temperature stablilities used in optoelectronics [6]. The 2D perovskites are obtained by

\footnotetext{
${ }^{1}$ Beijing Key Laboratory of Novel Thin-Film Solar Cells, Beijing Key Laboratory of Energy Safety and Clean Utilization, North China Electric Power University, Beijing 102206, China

${ }^{2}$ Center for Green Research on Energy and Environmental Materials, National Institute for Materials Science, Tsukuba 305-0047, Japan

${ }^{3}$ Department of Mathematics, Quaid-I-Azam University, Islamabad 44000, Pakistan

${ }^{4}$ NAAM Research Group, Faculty of Science, King Abdulaziz University, Jeddah 21589, Saudi Arabia

* Corresponding authors (emails: dingy@ncepu.edu.cn (Ding Y); tanzhanao@ncepu.edu.cn (Tan Z); sydai@ncepu.edu.cn (Dai S))
} 


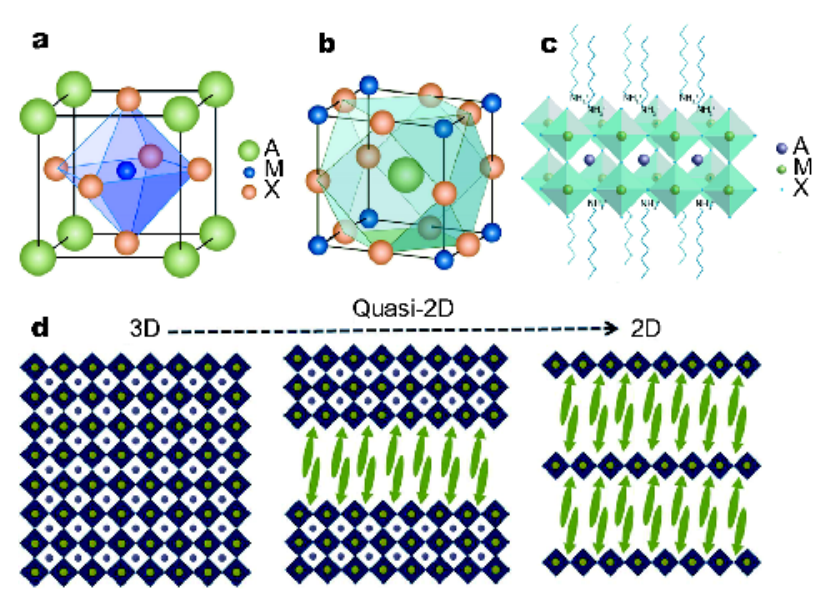

Figure 1 Structure diagrams of 3D perovskite lattices [7]: (a) $\mathrm{MX}_{6}$ regular octahedral structure; (b) $\mathrm{AX}_{12}$ cubic octahedral structure. (c) The structure diagram of $2 \mathrm{D}$ perovskite crystals [8]; (d) perovskite lattices with different dimensions $(n=\infty, 3 \mathrm{D}$ structure; $n=1$, pure $2 \mathrm{D}$ structure; and $n=$ defined integer, quasi-2D structure). Reprinted with permission from Ref. [7], Copyright 2014, Wiley-VCH Verlag GmBH\&, and Ref. [8], Copyright 2015, American Chemical Society.

inserting large-group ammonium halides (L) into inorganic $3 \mathrm{D}$ perovskite crystals, thus resulting in the structure of alternately stacked organic and inorganic layers (Fig. 1c). By changing the stoichiometric ratio of $\mathrm{LX}, \mathrm{AX}$, and $\mathrm{MX}_{2}$, quasi-2D perovskite $\left(\mathrm{L}_{2} \mathrm{~A}_{n-1} \mathrm{M}_{n} \mathrm{X}_{3 n+1}\right)$, with dimension between pure-2D perovskite $\left(\mathrm{L}_{2} \mathrm{MX}_{4}\right)$ and $3 \mathrm{D}$ perovskite $\left(\mathrm{AMX}_{3}\right)$ can be formed, as shown in Fig. 1d. The thickness of each inorganic layer can be incrementally adjusted by careful control of the stoichiometry, accompanied by the continuous control of band gap.

2D perovskites display good moisture stability compared with 3D perovskites owing to the hydrophobic alkylamines in their structures, which can prevent or delay the direct exposure of perovskite crystals to moisture $[6,9]$. Furthermore, the binding energy of $2 \mathrm{D}$ perovskite is significantly enhanced (up to $300 \mathrm{meV}$ [10]) compared with $3 \mathrm{D}$ perovskite, promoting the exciton radiative recombination efficiency. Some $2 \mathrm{D}$ perovskites with large-group organic cations like $\mathrm{C}_{6} \mathrm{H}_{5}\left(\mathrm{CH}_{2}\right)_{2} \mathrm{NH}_{3}{ }^{+}$ $\left(\mathrm{PEA}^{+}\right), \mathrm{IC}_{2} \mathrm{H}_{4} \mathrm{NH}_{3}^{+}\left(\mathrm{CA}^{+}\right)$or $\mathrm{C}_{10} \mathrm{H}_{7} \mathrm{CH}_{2} \mathrm{NH}_{3}{ }^{+}\left(\mathrm{NMA}^{+}\right)$ tend to form multiple phases of mixed dimensions [1113]. These phases with different exciton energies can be considered as multiple quantum wells (MQWs) and act as the carrier concentrators, leading to efficient radiative recombination $[11,12]$. Furthermore, due to the large dielectric constant of large-group ammonium halides, $2 \mathrm{D}$ perovskite theoretically has inferior carrier mobility and carrier diffusion length with the increasing proportion of organic component. Fortunately, 2D perovskite is highly anisotropic because of its inherent organic-inorganic stacking structure, which signifies that the charge transport ability could be improved by out-of-plane crystal growth. Vertical growth of inorganic layer is related to the species and proportions of organic cations as well as preparation methods $[6,14-16]$. The $2 \mathrm{D}$ perovskite film is isotropy when the proportion of large-group ammonium halides is small. By further increasing the proportion of large-group ammonium halides, the $2 \mathrm{D}$ perovskite film tends to show a vertical growth orientation [14]. 2D perovskite thin films of nearsingle-crystalline quality can be obtained by hot-cast method with near-perfect vertical orientation of the inorganic slabs [6]. In a word, $2 \mathrm{D}$ perovskite is characterized by improved stability and excitonic confinement properties compared with 3D perovskite, and its charge transport ability is believed comparable to that of traditional 3D perovskite using orientation engineering. Further researches about these material properties and devices applications are necessary for $2 \mathrm{D}$ perovskite, which may also provide other available choices for novel optoelectronic materials and applications in the future.

\section{Fundamental working principles of perovskite optoelectronic devices}

Perovskite materials are widely used in the fields of solar cells (SCs) and light-emitting diodes (LEDs). In these optoelectronic devices, perovskite plays the roles of absorber or emitter, as shown in the device structure in Fig. 2a. Perovskite solar cells (PeSCs) and perovskite light-emitting diodes (PeLEDs) are divided into PIN type and NIP type according to preparation order of hole transport layer (HTL)/perovskite layer/electron transport layer (ETL) or ETL/perovskite layer/HTL. In the PeSCs, 


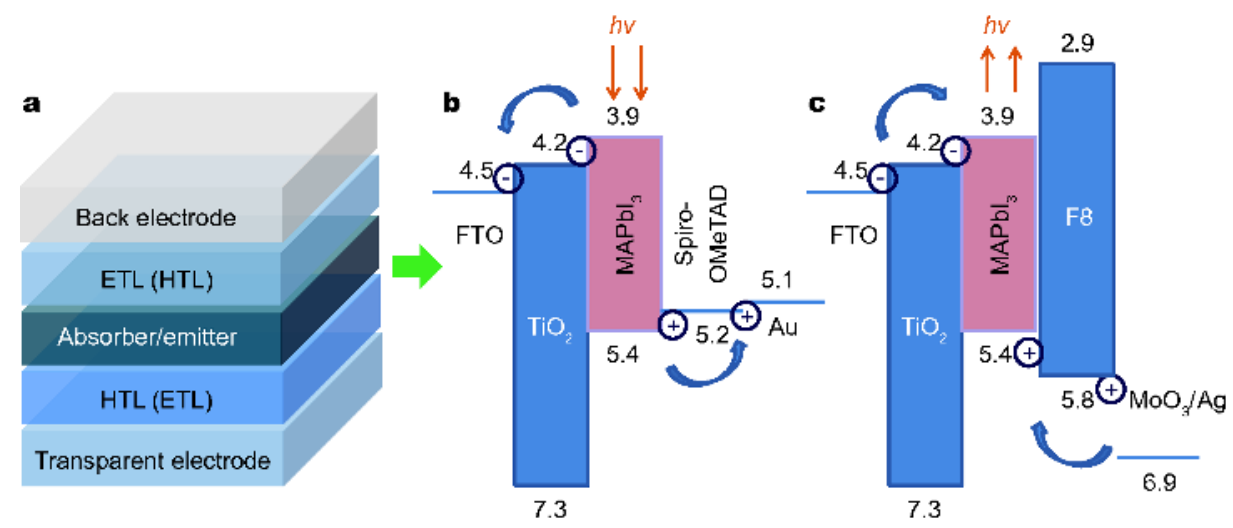

Figure 2 (a) Device structure of perovskite optoelectronic devices; (b) energy level diagram of PeSC; (c) energy level diagram of PeLED.

the structure in Fig. 2b for example, perovskite layer absorbs the photon energy, and free carriers are generated under illumination. The photo-induced electrons are then transferred into ETL driven by the energy gaps of different layers, and the photo-induced holes are transferred into HTL. Finally, carriers are collected by the electrodes and transmitted to an external circuit. For the opposite process of electron-generation, in PeLEDs (Fig. 2c), the electrons and holes are injected from ETL and HTL, and finally transferred into light emission through radiative recombination in the perovskite layer.

For traditional PeSCs, the thickness and qualities of perovskite layer including film crystallinity, coverage, and grain size, are important factors to favourable charge separation (recombination) and charge transport in them. For the PeSC, the increase of thickness of perovskite layer benefits light absorption. On the other hand, the film thickness is supposed to be less than the carrier diffusion length to ensure efficient charge transport. Thus, the tradeoff device performance requires long diffusion length of perovskite film to obtain high device performances [17]. For PeLED, the emitting region is confined to the perovskite layer to obtain pure-colour-light, so the perovskite layer is required to be thick enough. However, perovskite layer with superfluous thickness may provide more nonradiative recombination centres, which decreases the emitting efficiency of devices. Therefore, the PeLED also demands the optimal thickness of perovskite layer for the best device performance. Furthermore, high quality perovskite layer is another significant factor for good device performance, which means the high crystallinity, complete coverage and large grain size of perovskite layer. High quality perovskite film has more effictive carrier dissociation/transport and longer carrier diffusion length, with less ineffective recombination from pinholes and grain boundaries $[17,18]$. The crystal growth kinetics are closely related to surface property of substrate, composition and concentration of precursors, additives, annealing temperature, and atmosphere condition [19-22]. Controlling the procedure of nucleation and growth during film deposition and annealing is a promising route to morphology management and device optimization [23,24]. For large-area preparation, it is generally difficult to obtain high-quality perovskite films, leading to moderate device efficiency. To overcome this challenge, several processes, such as doctor blading [25], vapour-assisted deposition [26], pressure processing method [27], soft-cover deposition [28], were proposed to fabricate large-area homogeneous perovskite films.

Similar to 3D PeSCs as described above, the thickness and quality of active layer are also crucial factors for 2D PeSCs. In addition to these factors, the distinct properties of $2 \mathrm{D}$ perovskite, including the material stability, excitonic confinement in multiple quantum wells, charge transport ability related to component ratio and crystal orientation, also play critical roles for device application. These properties will be detailed introduced in the next section, and the influence on device performance will be summarized in the Application section.

\section{TYPICAL PROPERTIES OF 2D PEROVSKITE}

In comparison to traditional 3D perovskite, $2 \mathrm{D}$ perovskite is featured by inserted organic layers between inorganic crystals. Owing to the layered structure of alternatelystacked organic and inorganic layers, 2D perovskite materials have superior stability and enhanced excitonic properties. What's more, as the ratio of organic 
component increases, engineering of vertical crystal growth is important to achieve efficient charge transport.

\section{Superior material stability}

\section{Organic cations in $2 D$ perovskites}

Compared to $3 \mathrm{D}$ perovskite, organic cations in $2 \mathrm{D}$ perovskite are not constrained within the octahedral structure anymore. Since 2D perovskite materials were first synthesized, various organic cations were employed to fabricate $2 \mathrm{D}$ perovskites, including linear alkylamine and some large-group ammoniums (such as phenylamine and its derivatives, polymeric ammoniums). Besides monoammonium, there are also diammonium among these organic molecules.

Early in the 1970s, researchers had published papers about $2 \mathrm{D}$ perovskite materials in theoretical modelling [29-34]. At the same time, initial experiments were focused on pure-2D perovskite materials with linear alkylamine organic cations, $\left(\mathrm{C}_{n} \mathrm{H}_{2 n+1} \mathrm{NH}_{3}\right)_{2} \mathrm{MX}_{4}$, in which $\mathrm{M}$ represents metal cations including $\mathrm{Cd}^{2+}, \mathrm{Mn}^{2+}, \mathrm{Fe}^{2+}$, $\mathrm{Cu}^{2+}, \mathrm{Pb}^{2+}$ etc., and $\mathrm{X}$ represents anions including $\mathrm{Cl}^{-}, \mathrm{Br}^{-}$, $\mathrm{I}^{-}$. In subsequent $1990 \mathrm{~s}$, investigators started to synthesise and research quasi-2D perovskite materials, $\left(\mathrm{C}_{4} \mathrm{H}_{9} \mathrm{NH}_{3}\right)_{2}$ $\left(\mathrm{CH}_{3} \mathrm{NH}_{3}\right)_{n-1} \mathrm{M}_{n} \mathrm{I}_{3 n+1}$, which contains two kinds of organic cations in the structure [35-37]. One of the two molecules must be sufficiently small to satisfy the tolerance limits, thus steadily existing in the gap of metal-halogen octahedron frame, named as small organic cation (A). The other kind of cation has large groups to separate inorganic crystals to form stack structure named as L.

According to Goldschmidt tolerance-factor formula, the size of L-organic cations is confined in a certain scope. When below or above the scope, 2D perovskite structures cannot be formed. Organic cations and inorganic lattices are mismatched when the size exceeds the maximum; while the inorganic crystals cannot be separated when the size is below the minimum $[7,38]$. However, $\left(\mathrm{CH}_{3} \mathrm{NH}_{3}\right)_{2} \mathrm{PdCl}_{4}$ crystals can be prepared employing the small organic cation $\mathrm{CH}_{3} \mathrm{NH}_{3}{ }^{+}$, of which the size is below the tolerance factor threshold [39]. $\left(\mathrm{CH}_{3} \mathrm{NH}_{3}\right)_{2} \mathrm{PdCl}_{4}$ material has a direct optical band gap $\left(E_{\mathrm{g}}\right)$ of $2.22 \mathrm{eV}$, body resistivity of $1.4 \Omega \mathrm{cm}$, and absorption coefficient of $10^{4} \mathrm{~cm}^{-1}$ orders of magnitude. The $\mathrm{CH}_{3} \mathrm{NH}_{3}{ }^{+}$could be the smallest organic cation forming $2 \mathrm{D}$ perovskite by now.

In recent years, various large-group ammonium halides have been developed, as shown in Fig. 3a, consisting of phenylamine and its derivatives, $\mathrm{C}_{6} \mathrm{H}_{5} \mathrm{C}_{n} \mathrm{H}_{2 n} \mathrm{NH}_{3}{ }^{+}$[41-45] and the polymeric ammonium $[40,46]$, such as poly- ethylenimine (PEI). Besides monoammonium cations $\left(\mathrm{RNH}_{3}{ }^{+}\right)$, diammonium cations $\left({ }^{+} \mathrm{NH}_{3} \mathrm{RNH}_{3}{ }^{+}\right)$are also employed to form an organic spacing layer. Fig. 3b, c show the structure diagrams of $\langle 110\rangle$ oriented layered perovskite with monoammonium and diammonium cations [47]. In monoammonium cations, ammonium groups interact with inorganic sheets by hydrogen bond and ionic bond, and tails extend to the organic layer space. For some monoammonium cations, the tails and adjacent inorganic layer interlace together; otherwise, the tails interact with surrounding tails by van der Waals force, apart from the inorganic layer. When there is no interaction between organic cations, the benzene or hexafluorobenzene are always inserted into the organic layers to fix the bimolecular combination, as shown in Fig. 3d. This is because of the interactions between fluoroaryls or aryls [48]. Diammonium cations have two ammoniums, one at each end, bonding with adjacent inorganic layers severally and stretching across the whole organic layer.

\section{Mechanism of superior material stability}

The stability enhancement of $2 \mathrm{D}$ perovskite materials is related to the multiple interaction forces in 2D perovskite, including strong ionic bond and covalent bond within inorganic layer, weak van der Waals force within organic layer, as well as connections between organic and inorganic layers (coordination bonds between ammonium group and $\mathrm{Pb}$, hydrogen bond between ammonium group and halogen). Compared with 3D perovskite structure, 2D perovskite has organic cations extending to a wider space and interacting with each other by van der Waals force. As a result, it needs higher energy to interrupt interaction between the large-group ammoniums and inorganic layers in $2 \mathrm{D}$ structure than in $3 \mathrm{D}$ structure with $\mathrm{MA}^{+}$cations. Accordingly, desorption rate of organic cations is reduced by 6 orders of magnitude, while relevant decomposition process is slowed down as much as 1,000 times [49]. Furthermore, the organic cations on perovskite crystal surface can act as protective shell against moisture in the air. Study with density function theory (DFT) shows that decomposition reaction begins spontaneously on the material surface instead of inside the perovskite crystal, resulting from greater degree of freedom to rearrange surface molecules [49]. Thus, hydrophobic organic cations in 2D perovskite can effectively resist moisture in the air and prevent inorganic crystals from being damaged. The $2 \mathrm{D}$ PeSCs remain stable in air for several months, while the 3D counterparts begin to degrade after just a few days. 


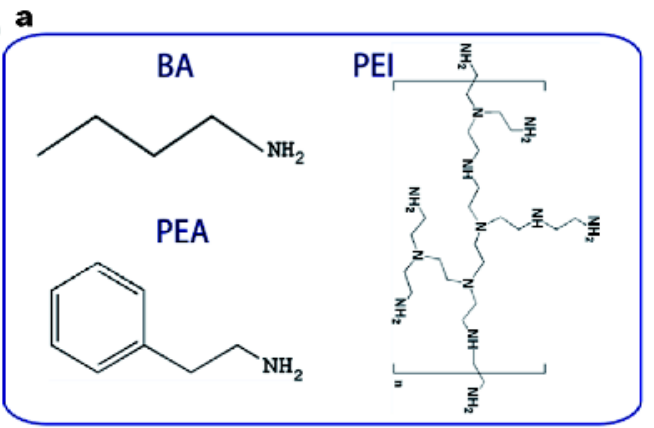

b

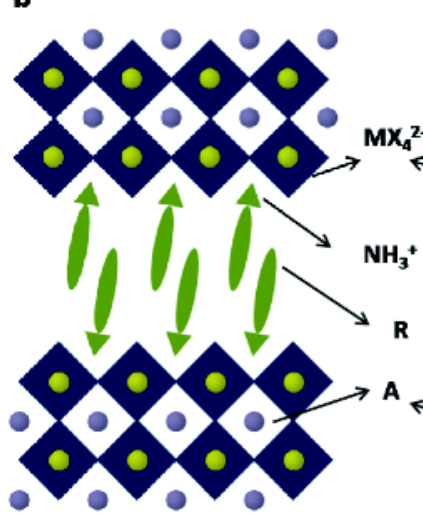

c
$(\mathrm{BA})_{2} \mathrm{PbBr}_{4} \quad\left(\mathrm{C}_{6} \mathrm{H}_{5} \mathrm{CH}_{2} \mathrm{NH}_{3}\right)_{2} \mathrm{PbBr}_{4}$

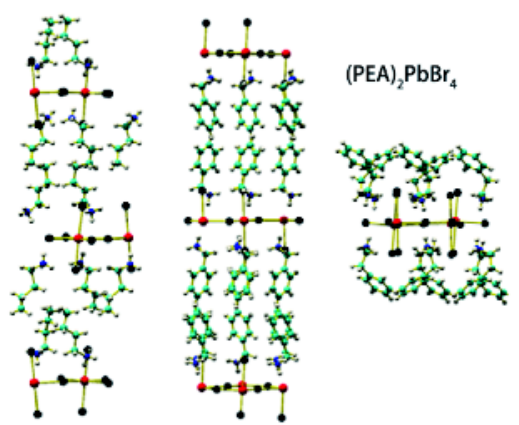

d

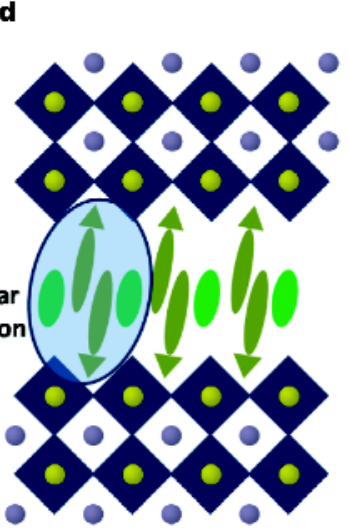

Figure 3 (a) Typical large-group ammoniums and structure of corresponding 2D perovskite crystal [40,41]; structure diagrams of 2D perovskite with (b) monoammonium cations and (c) diammonium cations. (d) Bimolecular combination fixed by interactions between fluoroaryls or aryls in 2D perovskite. Reprinted with permission from Ref. [40], Copyright 2016, American Chemical Society, and Ref. [41], Copyright 2014, American Chemical Society.

Suppressed ion migration in 2D perovskite is another potential reason for its excellent stability. The ion conductivity and ion migration activation energy both in the dark and under illumination were measured by Lin et al. [50] to investigate the ion migration stability in these materials. Under illumination, the conductivity should be mainly attributed to the photogenerated carriers. While in the dark conditions, the electronic conduction is the dominant contribution to the conductivity in the "low-temperature region" because ion migration is suppressed. With further increase in temperature, 3D perovskite shows a transition process from electronic to ionic conductivity with the activation energy changed from 30 to $190 \mathrm{meV}$. By contrast, such transition process is not observed in $2 \mathrm{D}$ perovskite with the constant activation energy of $41 \pm 7 \mathrm{meV}$, which illustrates that the ion migration is suppressed because of the organic spacing layer. This character of $2 \mathrm{D}$ perovskite could alleviate the deterioration process caused by ion migration, including the formation of nonradiative recombination centres, the decomposition of active layer, the degradation of transport layers and corrosion of electrodes.

Quantum confinement effect and exciton properties in 2D perovskite

Quantum confinement effect

Similar to other low-dimensional materials, 2D perovskite, has quantum confinement effect [51]. The 2D perovskite has a wider band gap and narrow photoluminescence (PL) peak compared with the 3D analogue $[42,52]$. The bandgap can be directly tuned by changing the "thickness" of inorganic layers. With increased $n, 2 \mathrm{D}$ perovskite exhibits weakened excitonic and enhanced electronic properties and displays a transition from semiconducting to metallic behaviour [35]. Table 1 shows the band gap $\left(E_{\mathrm{g}}\right)$ values of several typical $2 \mathrm{D}$ perovskite materials with different $n$.

As mentioned above, the perovskite dimension can be adjusted by controlling stoichiometric. Interestingly, some quasi-2D perovskite films are not in single phase 
Table 1 The band gap of typical 2D perovskite materials $(\mathrm{eV})$

\begin{tabular}{cccccc}
\hline 2D-perovskite materials & $n=1$ & $n=2$ & $n=3$ & $n=\infty$ & Ref. \\
\hline$(\mathrm{BA})_{2}(\mathrm{MA})_{n-1} \mathrm{~Pb}_{n} \mathrm{I}_{3 n+1}{ }^{\mathrm{a}}$ & 2.24 & 1.99 & 1.85 & 1.52 & {$[14]$} \\
$(\mathrm{PEA})_{2}(\mathrm{MA})_{n-1} \mathrm{~Pb}_{n} \mathrm{I}_{3 n+1}{ }^{\mathrm{b}}$ & 2.57 & 2.32 & $/$ & 1.61 & {$[53]$} \\
$(\mathrm{PEI})_{2}(\mathrm{MA})_{n-1} \mathrm{~Pb}_{n} \mathrm{I}_{3 n+1}{ }^{\mathrm{c}}$ & $/$ & $/$ & 1.79 & 1.58 & {$[40]$} \\
$\left.(\mathrm{AVAI} / \mathrm{PbI})_{2}\right) /\left(\mathrm{MAI} / \mathrm{PbI}_{2}\right)^{\mathrm{d}}$ & $/$ & $/$ & $1.69(3 \%)$ & 1.63 & {$[54]$} \\
\hline
\end{tabular}

a) $\mathrm{BA}=\mathrm{CH}_{3}\left(\mathrm{CH}_{2}\right)_{3} \mathrm{NH}_{3}{ }^{+}, \mathrm{MA}=\mathrm{CH}_{3} \mathrm{NH}_{3}{ }^{+}$; b) $\mathrm{PEA}=\mathrm{C}_{6} \mathrm{H}_{5}\left(\mathrm{CH}_{2}\right)_{2} \mathrm{NH}_{3}{ }^{+}$; c) $\mathrm{PEI}=$ polyethylenimine, $\left.\left(\mathrm{CH}_{2} \mathrm{CH}_{2} \mathrm{NH}\right)_{n} ; \mathrm{d}\right) \quad \mathrm{AVAI}=\mathrm{HOOC}\left(\mathrm{CH}_{2}\right)_{4} \mathrm{NH}_{3} \mathrm{I}$, $E_{\mathrm{g}}=1.69 \mathrm{eV}$ when $\left(\mathrm{AVAI} / \mathrm{PbI}_{2}\right)$ take up $3 \%$ of the total volume.

but multiple phases of mixed dimensions [11-13,49,55]. For pure-2D perovskite $(n=1)$, there is only one phase named P1, corresponding to the only absorption peak for $n=1$ perovskite in Fig. 4 a. When $n$ is small, the phases P1, $\mathrm{P} 2$, and $\mathrm{P} 3$ are dominant. As the proportion of pure-2D component increased $(n=2,3,4 \ldots)$, the quasi-2D perovskite films show different crystal phases with diverse dimensions, corresponding to several absorption peaks. The overlapped PL peaks of quasi-2D perovskite at about $520 \mathrm{~nm}$ separated from that of pure-2D perovskite can also imply these multiple phases in quasi-2D perovskite
(Fig. 4b). All the PL peaks of quasi-2D perovskite films are nearly at the same position of the PL peak of pure-3D perovskite. This phenomenon is related to the exciton confinement and photoexcitation transfer along different phases and the PL is generated from the phase with smallest bandgap (Fig. 4c-e).

\section{Exciton confinement and photoexcitation transfer}

Since their spatial-confinement layered nanostructures, $2 \mathrm{D}$ perovskite can be considered as quantum-well structure, where the organic layers act as "barriers" and
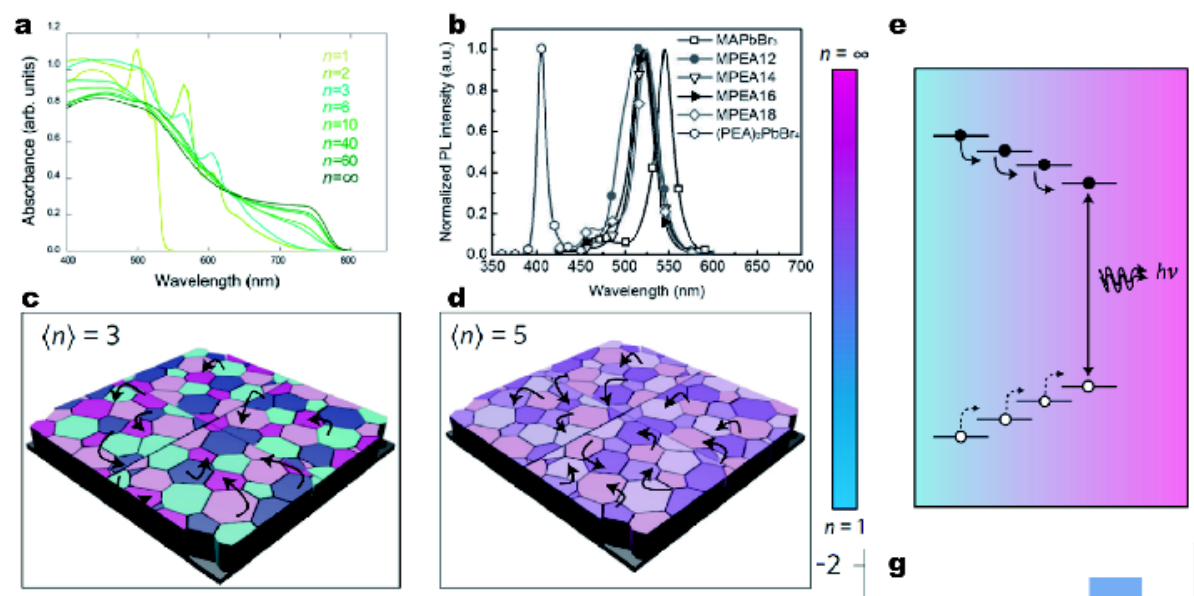

d
$\langle n\rangle=5$
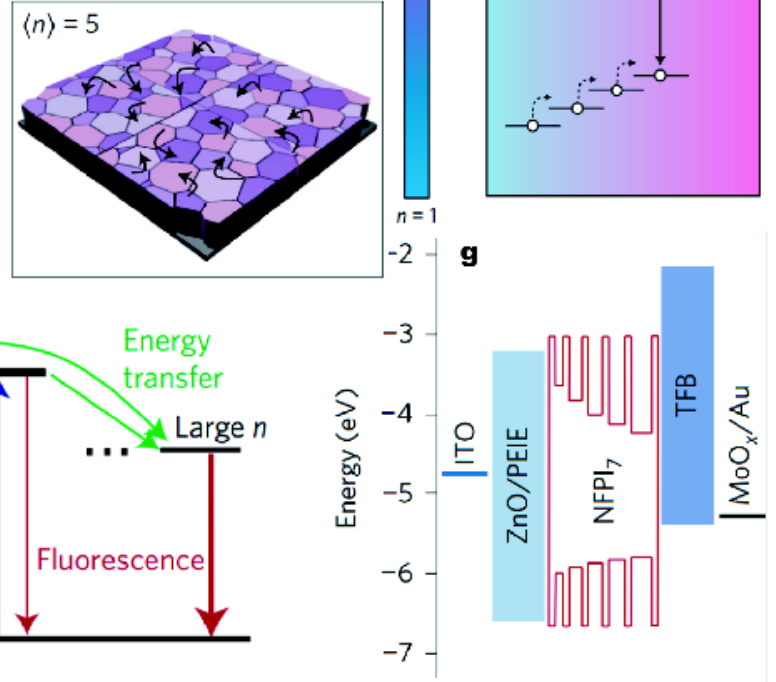

Figure 4 (a) The absorption [49] and (b) PL [55] spectra of (PEA) $\mathrm{MA}_{n-1} \mathrm{~Pb}_{n} \mathrm{I}_{3 n+1}$. The carrier transfer process in (c) $n=3$ and (d) $n=5$ multiple-phase $(\mathrm{PEA})_{2} \mathrm{MA}_{n-1} \mathrm{~Pb}_{n} \mathrm{I}_{3 n+1}$ and (e) the energy transfer across an inhomogeneous energy landscape [12]. (f) Schematic of cascade energy transfer in NFPI MQWs and (g) the energy level diagram of the MQWs solar-cell device [11]. Reprinted with permission from Ref. [49], Copyright 2016, American Chemical Society; Ref. [55], Copyright 2015, Wiley-VCH GmBH\&Co.; Ref. [12], Copyright 2016, Nature Publishing Group; Ref. [11], Copyright 2016, Nature Publishing Group. 
the inorganic layers as "wells". The excitons are bound in the built-in electric field between the positive organic layer and the negative inorganic layer. For the III-V group's semiconductor, such as heterojunction GaAs/AlAs/GaAs, excitons can only exist stably at low temperature, rather than room temperature [56]. Conversely, excitons in $2 \mathrm{D}$ perovskite can exist stably at room temperature due to the Cullen medium shielding effect [57]. There exists a dielectric-constant mismatch between organic layer and inorganic layer, leading to enhanced exciton effect in $2 \mathrm{D}$ perovskite. The binding energy of $\left(\mathrm{C}_{n} \mathrm{H}_{2 n+1} \mathrm{NH}_{3}\right)_{2} \mathrm{PbI}_{4}$ is measured as large as $320-420 \mathrm{meV}$ $[33,58,59]$ compared with $6-90 \mathrm{meV}$ of $\mathrm{CH}_{3} \mathrm{NH}_{3} \mathrm{PbI}_{3}$ $[60,61]$. However, strong luminescence is only obtained at liquid nitrogen temperature, which is not so clearly understood but tentatively ascribed to exciton thermal quenching [52,62].

Furthermore in some quasi-2D perovskite films, selforganized multiple quantum wells (MQWs) with different exciton energies are found aligning in certain tendency [11]. Large- $n$ QWs and small- $n$ QWs tend to locate at interfaces between perovskite/HTL and perovskite/ETL respectively (Fig. 4f, g). The multiple phases of mixed dimensions act as carrier concentrators that provide a funnelling mechanism for excited carriers transport. This rapid energy transfer restricts the exciton quenching effect and helps efficient radiative recombination in large- $n$ QWs with better emission properties, resulting in improved performance of PeLEDs. However, this property is not in favour of the sequential colour tuning in some quasi-2D PeLEDs because of the similar PL peaks for different dimensions. It is not ubiquitous for all kinds of $2 \mathrm{D}$ perovskite to form multiple phases of mixed dimensions. For example, $(\mathrm{BA})_{2}(\mathrm{MA})_{n-1} \mathrm{~Pb}_{n} \mathrm{I}_{3 n+1}$ and $(\mathrm{PEI})_{2}(\mathrm{MA})_{n-1} \mathrm{~Pb}_{n} \mathrm{I}_{3 n+1}$ perovskite show no obvious evidence for multiple phases. In contrast, $(\mathrm{BA})_{2}(\mathrm{MA})_{n-1}$ $\mathrm{Pb}_{n} \mathrm{I}_{3 n+1}$ perovskite is likely to form near-single-crystalline films when $n>2$ in some cases [6].

This exciton confinement property is favourable to $2 \mathrm{D}$ perovskites as ideal light-emitting materials. As a result, 2D PeLEDs show higher external quantum efficiency (EQE) compared with homologous 3D structures owing to more efficient radiation recombination and less exciton-defect quenching. However, with a larger proportion of insulating layers (smaller $n$ ), the electronic properties of $2 \mathrm{D}$ perovskite make it imperfect as solarcell absorber for the increased exciton binding energy as well as the decreased charge separation and transport abilities. The charge transport ability can be improved by engineering the vertical orientation of inorganic layers

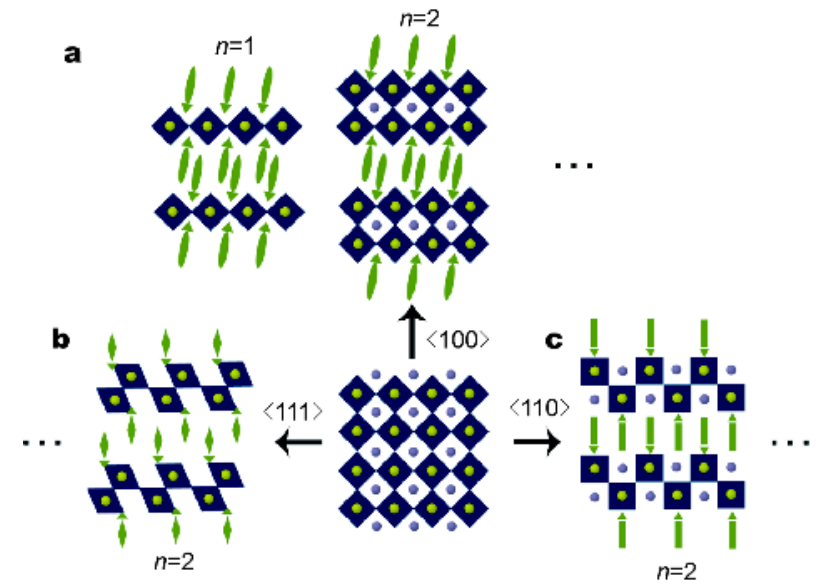

Figure 5 Structure diagrams of 2D perovskite with several orientations.

$[6,14-16]$.

\section{Crystal orientations engineering}

There are multiple crystal planes in 3D perovskite, including $\langle 100\rangle,\langle 110\rangle$ and $\langle 111\rangle$, leading to different growth orientations in low-dimension structures [47] (Fig. 5). For the pure-2D perovskite $(n=1)$, only $<100>$ oriented planes favour the continuous growth of inorganic layers to form the simplest and commonest kinds of $2 \mathrm{D}$ perovskites. The $\langle 110\rangle$ and $\langle 111\rangle$ oriented planes grow continuous inorganic layer only when $n>1$. 2D perovskites with different organic cations tends to develop distinct oriented perovskite crystals. For example, in solution-processed 2D perovskite which contains only alkylammonium halides and tin (II) or leads (II) iodide, there appears almost no $\langle 110\rangle$ direction, and the iodoformamidinium cation tends to form $<110\rangle$ rather than $<100>$ oriented crystals [63].

\section{Orientations engineering by stoichiometry ratio}

For $2 \mathrm{D}$ perovskite materials, the crystal orientation on substrate shows obvious tendency when carefully controlling the stoichiometry ratio [6,14-16]. Oriented crystallisation parallel to substrate contributes to the growth of charge transport channel in inorganic layers, and thus assists in carrier transportation $[6,14]$. We take $(\mathrm{BA})_{2}(\mathrm{MA})_{n-1} \mathrm{~Pb}_{n} \mathrm{I}_{3 n+1}$ as an example. For the $n=1$ member, the pure-2D perovskite $(\mathrm{BA})_{2} \mathrm{PbI}_{4}$ preferentially grows along the (110) direction where the inorganic planes parallel to the substrate. When $n>1$, there occurs a competition between parallel and vertical growth caused by BA and MA cations, where BA favours the growth within the planer layer and MA facilitates the growth outside the layer. As a result, in the $n=2$ member, there 

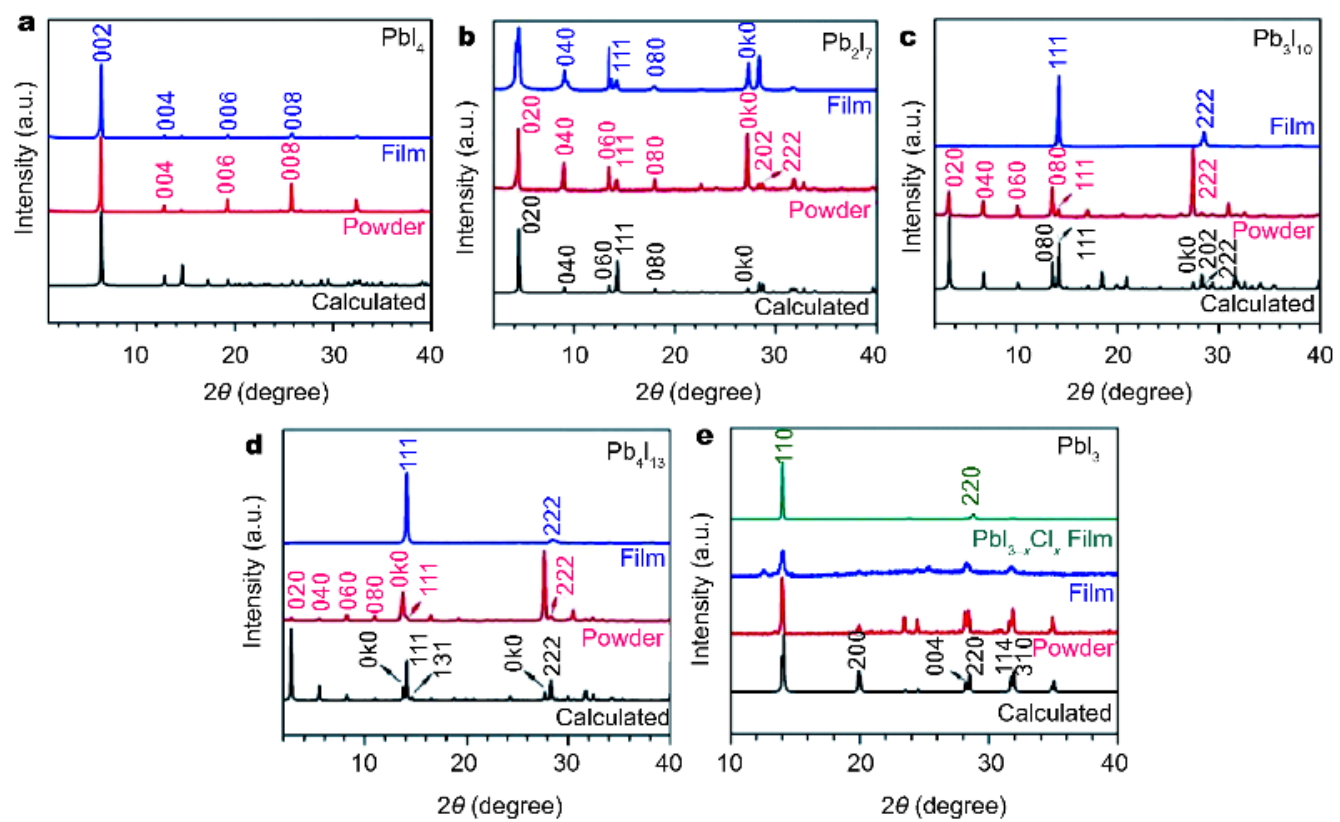

Figure 6 The XRD spectra of 2D perovskite $(\mathrm{BA})_{2}(\mathrm{MA})_{n-1} \mathrm{~Pb}_{n} \mathrm{I}_{3 n+1}(n=1,2,3,4)$ and 3D perovskite $\mathrm{MAPbI}_{3}(n=\infty)$ powders or films [14]. Reprinted with permission from Ref. [14], Copyright 2015, American Chemical Society.

exist both parallel and vertical growth; for $n>2$ compounds, the crystal orientation would be vertical to the substrate plane in priority, and thin films with nearsingle-crystalline quality are finally produced. This crystal orientation was probed by scanning electron microscope (SEM), X-ray diffraction (XRD) and grazing incidence wide-angle X-ray scattering (GIWAXS) tests.

$\mathrm{XRD}$ is a powerful technique to identify the structure of $2 \mathrm{D}$ perovskite. The diffraction peaks of a crystal zone are almost equidistant, and the thickness of inorganic layer and organic layer can be derived from XRD patterns [15]. Fig. 6 shows XRD spectra of quasi-2D perovskite of $(\mathrm{BA})_{2}(\mathrm{MA})_{n-1} \mathrm{~Pb}_{n} \mathrm{I}_{3 n+1}(n=1,2,3,4, \infty)$ [14]. The pure-2D perovskite $(n=1)$ shows $(00 k)$ peaks implying the preferential growth along (110) direction. For the quasi-2D perovskite powder $(n=2),(0 k 0)$ reflections occur in addition to (111) and (222) in the obtained XRD spectra corresponding to in-plane and out-of-plane orientations. In contrast, merely (111) and (222) reflections are noticed obviously for $n=3$ and $n=4$ quasi-2D perovskite films ((110) and (220) analogously for $n=\infty)$, which implies the vertical growth orientation of $(\mathrm{BA})_{2}(\mathrm{MA})_{n-1} \mathrm{~Pb}_{n} \mathrm{I}_{3 n+1} 2 \mathrm{D}$ perovskite $(n=3,4)$. As $n$ further increases towards $3 \mathrm{D}$ perovskite, the preferential layer alignment fades because few $\mathrm{BA}$ cations dope in $3 \mathrm{D}$ perovskite and show no longer influence on orientations. The XRD difference between films and powers demonstrates the crystal growth is affected when the substrate considered. Film crystallinity and orientation can be observed from SEM images, where perpendicular growing on the substrate and complete coverage are found in BA-based quasi-2D perovskite film compared with MA-based 3D perovskite, which is beneficial to device performance.

\section{Orientations engineering by fabrication processes}

The vertical orientation is managed by the hot-cast method and therefore near-single-crystalline $(\mathrm{BA})_{2}(\mathrm{MA})_{3} \mathrm{~Pb}_{4} \mathrm{I}_{13}$ films are obtained as demonstrated in GIWAXS [6]. GIWAXS of room-temperature-spin-coating exhibits a series of diffraction rings with strong intensity at certain extended arc segments, indicating that the polycrystalline films orient randomly in 3D without consistent direction. On the contrary, the film prepared by hot-cast method shows sharp discrete Bragg spots corresponding to arc segments. It is concluded that the hot-cast films grow along certain orientations, confirmed by the most remarkable reflections of (111) and (202) planes. The inorganic crystal plates $<(\mathrm{MA})_{n-1} \mathrm{~Pb}_{n} \mathrm{I}_{3 n+1}>^{2-}$ are perpendicular to the substrate, forming continuous charge transfer channels favourable to charge transport for optoelectronic applications (Fig. 7b, e).

\section{Trade-off properties}

As mentioned above, with pure-2D component increased, the $2 \mathrm{D}$ perovskite has enhanced stability. But meanwhile, the organic layers with large dielectric constant may 


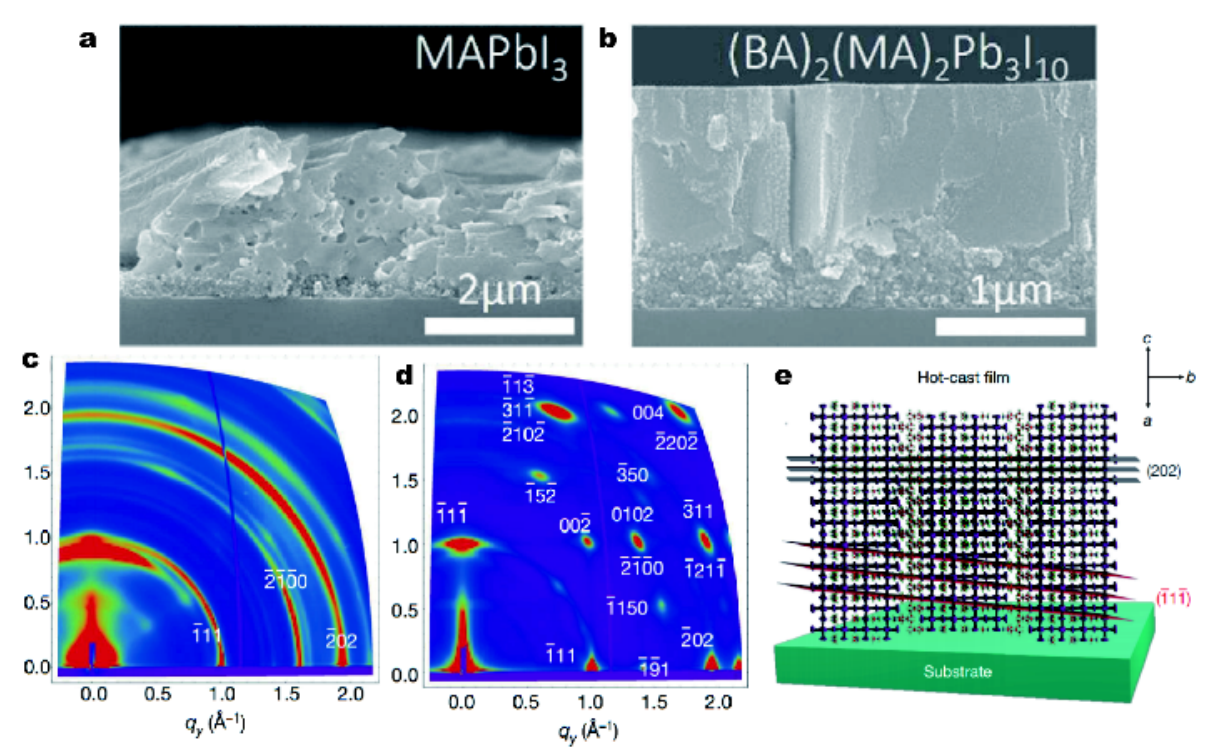

Figure 7 SEM images of (a) $\mathrm{MAPbI}_{3}$ film and (b) $(\mathrm{BA})_{2}(\mathrm{MA})_{2} \mathrm{~Pb}_{3} \mathrm{I}_{10}$ film [14]. GIWAXS patterns of $(\mathrm{BA})_{2}(\mathrm{MA})_{3} \mathrm{~Pb}_{4} \mathrm{I}_{13}$ films prepared by $(\mathrm{c})$ traditional room-temperature-cast method; (d) hot-cast method. (e) Structure diagram of the 2D perovskite crystal obtained from GIWAXS test [6]. Reprinted with permission from Ref. [14], Copyright 2016, American Chemical Society and Ref. [6], Copyright 2016, Nature Publishing Group.

weaken the charge transport properties. It is known that the charge-carrier mobility results from the interplay of quantum confinement effect, crystal orientations and trap passivation effect [16]. As the dimension changes from $3 \mathrm{D}$ to $2 \mathrm{D}$, the random orientations are replaced by ones perpendicular to the substrate, which is in favour of increased charge-carrier mobility. However, synchronously, exciton binding energy increases, trying to decrease the charge-carrier mobility and outweighing the benefits of preferential orientation when $n$ increases to a certain magnitude. Furthermore, as the insulating component increases, the monomolecular recombination rate decreases first due to the trap passivation and then increases because of exciton recombination. For these reasons, to achieve excellent device properties, it is crucial to balance electronic confinement, crystal orientations and trap reduction for good charge transport ability with favourable stability.

\section{PREPARATION METHODS OF 2D PEROVSKITE FILMS}

\section{Typical preparation methods of 3D perovskite films}

High-quality perovskite films are crucial for excellentperformance devices. For this purpose, researchers have proposed plenty of preparation methods of $3 \mathrm{D}$ perovskite films, mainly divided into three categories: one-step spincoating, co-evaporation, and sequential deposition. The one-step spin-coating method is the simplest and most common method $[5,18,66,67]$. Perovskite films prepared by this method contain uneven grains and plentiful pinholes due to the rapid chemical reaction during solvent volatilization, which results in the contact between substrate and the functional layer above perovskite layer. As a result, the devices generate large leakage current during operation [68]. To settle the question above, the fast deposition-crystallisation procedure (or antisolvent spin-coating) (Fig. 8a) [64,69] and the vacuum flash-assisted solution process [70] were reported successively for perovskite films preparation. The mechanism for the formation of dense and uniform perovskite films using these methods is analogical. During the antisolvent spinning (or the vacuum-flash process), the residual solvents are rapidly removed and the constituents are immediately frozen, leading to the formation of methylammonium iodide-lead iodide-dimethyl sulfoxide (MAI- $\mathrm{PbI}_{2}$-DMSO) intermediate phase. The DMSO retards the rapid reaction between $\mathrm{PbI}_{2}$ and MAI thus slowing down the crystal growth during solvent evaporation according to Equation 1: $\mathrm{PbI}_{2}$-DMSO$\mathrm{MAI} \rightarrow \mathrm{MAPbI}_{3}+\mathrm{DMSO} \uparrow$. As a result, dense and uniform perovskite films with increased grain size can be obtained after subsequent annealing. Besides one-step solution process, vapour deposition methods [71,72] and spraydeposition [26] were proposed. Perovskite films prepared by the vapour deposition methods are uniform and smooth with continuous coverage and excellent crystallinity. However, the cost is considerable because the 


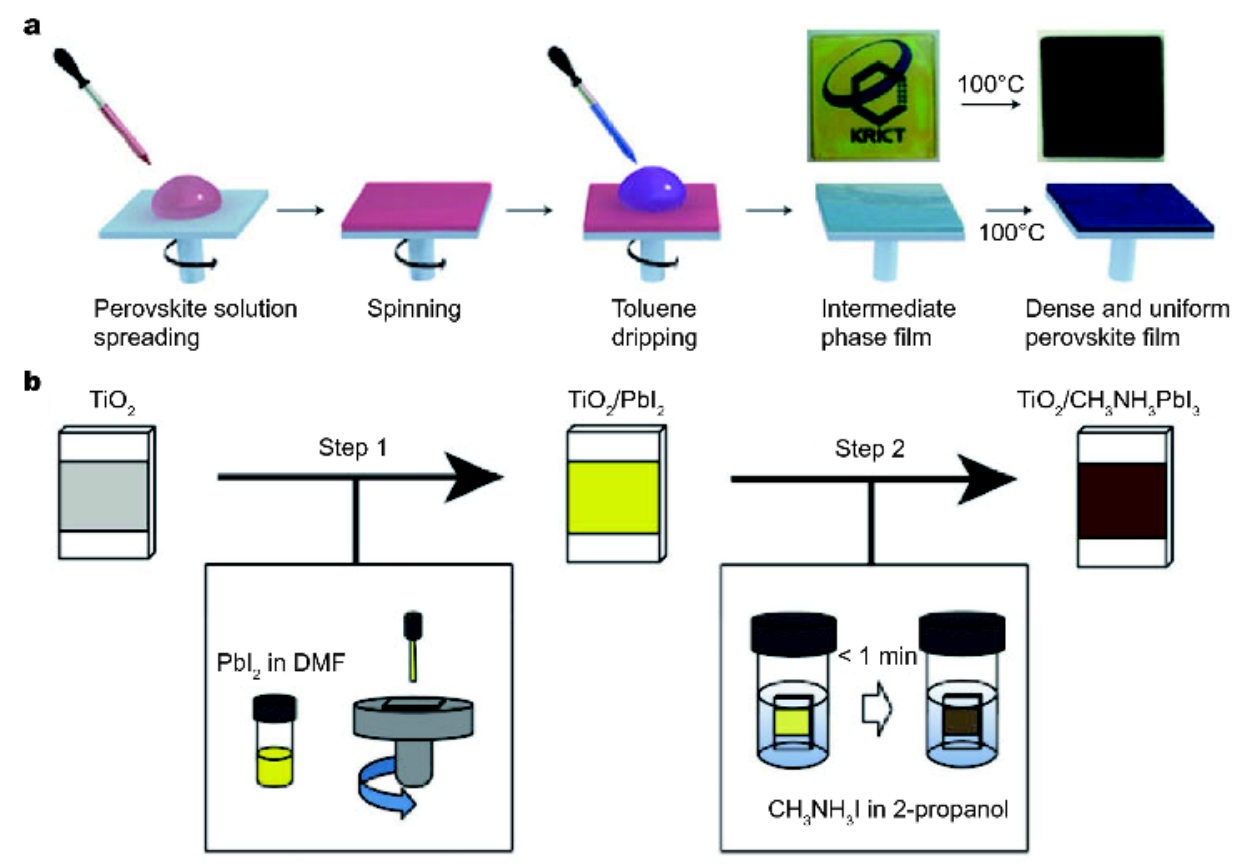

Figure 8 (a) Fast deposition-crystallisation procedure [64], and (b) sequential dipping method [65] of 3D perovskite films fabrication. Reprinted with permission from Ref. [64], Copyright 2013, Nature Publishing Group and Ref. [65], Copyright 2014, Nature Publishing Group.

experimental vacuum conditions are required. Therefore, they are not suitable for large-scale industrial production.

Sequential deposition is another kind of method for fabricating perovskite films, such as the dipping method (Fig. 8b) [65,73-75] and the sequential spin-coating $[76,77]$. However, this approach is not suitable for planar heterojunction structures because of the slow and incomplete reaction. The perovskite films prepared by dipping method are rough and deciduous in the absence of the mesoporous-skeleton layers. By contrast, sequential spin-coating is more applicable to prepare planar heterojunction structure. Compared with one-step spincoating method, films prepared by sequential deposition have complete coverage and uniform morphology. This is because that the well-covered $\mathrm{PbI}_{2}$ films act as the superior framework and provide kinetically favourable "nucleation" centers for further crystal growth, as shown in Equation 2: $\mathrm{PbI}_{2}+\mathrm{MAI} \rightarrow \mathrm{MAPbI}_{3}$. In addition to these methods, vapour assisted solution [68] and close space sublimation process [78] were also reported to fabricate perovskite films.

\section{Preparation methods of 2D perovskite films}

\section{One-step spin-coating methods}

Unlike the multiple preparation methods of 3D perovskite films, the preparation methods of 2D perovskite films are limited and expected to be enriched. Thus, the preparation methods of 3D perovskite films are supposed to be introduced in 2D perovskite films after fine-tuning. The majority of $2 \mathrm{D}$ perovskite films reported by now are prepared by one-step spin-coating methods [14,40, $49,79,80]$, to be specific, depositing precursor solutions (organics and metal halides dissolved in solvents, e.g., DMF or DMSO/GBL(1/1)) on substrates. By adjusting the ratio of the precursors, the dimension of perovskite is changed. This method is very simple and has been applied to fabricate $2 \mathrm{D}$ perovskite films in both n-i-p and p-i-n structures, such as $(\mathrm{PEA})_{2}(\mathrm{MA})_{n-1} \mathrm{~Pb}_{n} \mathrm{I}_{3 n+1},[49,79]$ $(\mathrm{BA})_{2}(\mathrm{MA})_{n-1} \mathrm{~Pb}_{n} \mathrm{I}_{3 n+1},[14]$ and $(\mathrm{PEI})_{2}(\mathrm{MA})_{n-1} \mathrm{~Pb}_{n} \mathrm{I}_{3 n+1}[40]$. The fast deposition-crystallisation procedure was also introduced into the fabrication of $2 \mathrm{D}$ perovskite. By dropping antisolvent, e.g., chlorobenzene, during the spin-coating process, homogeneous nuclei are formed immediately and grow up slowly. Finally, dense and uniform films are obtained without oversize grains that may destroy the morphology [49]. To achieve better device performances, the hot-cast method was introduced into (BA) $)_{2}(\mathrm{MA})_{3} \mathrm{~Pb}_{4} \mathrm{I}_{13}$ films on PEDOT:PSS substrate [6]. The FTO/PEDOT:PSS substrate was heated before the precursor solution spin-coated on it. Fig. 9a shows the photograph of $(\mathrm{BA})_{2}(\mathrm{MA})_{3} \mathrm{~Pb}_{4} \mathrm{I}_{13}$ films prepared on substrates with different hot-cast temperatures from room temperature $(\mathrm{RT})$ to $150^{\circ} \mathrm{C}$. With rising tempera- 


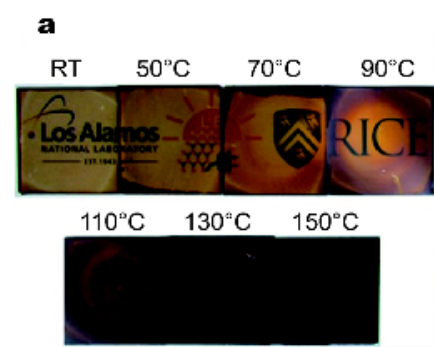

b

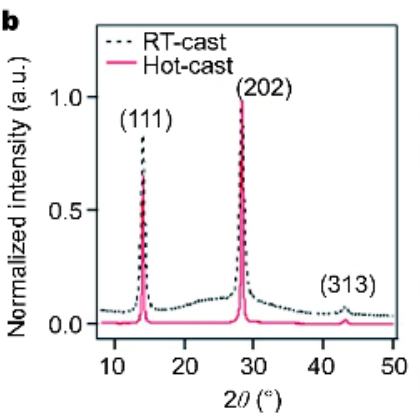

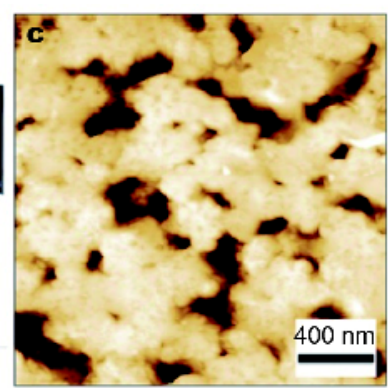
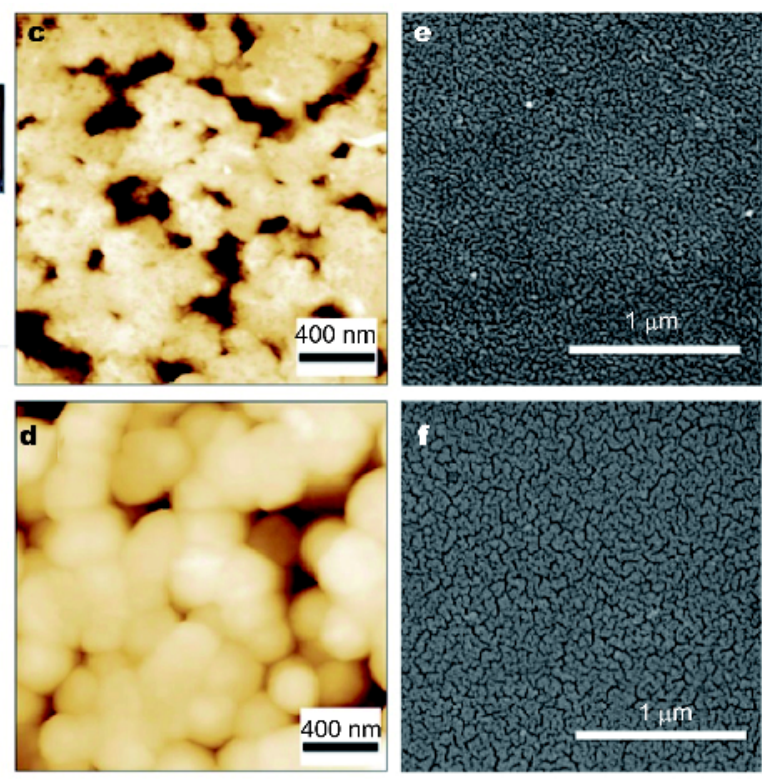

Figure 9 (a) The $(\mathrm{BA})_{2}(\mathrm{MA})_{3} \mathrm{~Pb}_{4} \mathrm{I}_{13}$ films cast from room temperature (RT) to $150^{\circ} \mathrm{C}$, (b) GIXRD spectra, (c, d) AFM images, and (e, f) SEM images of films prepared by traditional room-temperature-cast method (c, e) and hot-cast method (d, f) [6]. Reprinted with permission from Ref. [6], Copyright 2016, Nature Publishing Group.

ture, the films become dark and shiny with lower pinhole density (Fig. 9b-f), which is necessary for high-efficiency devices. Most importantly, the inorganic layers in 2D perovskite films prepared by the hot-cast method have a preferential orientation vertical to the substrate with excellent crystallinity and few carrier traps, which is in favour of charge transport.

Another solution vapour annealing method was used to prepare high-quality (PEA) ${ }_{2} \mathrm{PbBr}_{4}$ nanosheets at room temperature as an emitting layer for LEDs, as shown in Fig. 10a [81]. After emitting layer spin-coated, the sample was treated by solvent vapour annealing method. Firstly, a precursor solution of DMF comprising $\mathrm{PEABr}$ and $\mathrm{PbBr}_{2}(2 / 1)$ was spin-coated on the top of ITO/PEDOT: PSS substrate. The sample was then placed face down on the edge of a glass dish but without contacting it. After that, the dish was transferred into a lidded beaker filled with DMF to form a closed space with DMF vapour. The temperature of DMF solvent was kept at $30^{\circ} \mathrm{C}$ for several minutes before the DMF vapour diffused beneath the $(\mathrm{PEA})_{2} \mathrm{PbI}_{4}$ film and contacted with it. As soon as the film turning into purple, it was removed out into open air rapidly and heated at $100^{\circ} \mathrm{C}$ for $10 \mathrm{~min}$. By using DMF vapour annealing, the small and compact $(\mathrm{PEA})_{2} \mathrm{PbI}_{4}$ perovskite grains recrystallize into micron-sized nanosheets evenly distributed on PEDOT:PSS substrate. The nanosheet-films have larger grain size and higher crystallinity as well as higher PL intensity related to higher photoluminescence quantum yield (PLQY) (owing to quantum confinement) compared with unprocessed films (Fig. 10b-g). Furthermore, the nanosheet-films show a longer PL lifetime although it is still much lower than that of the 3D perovskite $\mathrm{MAPbI}_{3}$ (Fig. 10h). As for device performance, nanosheet-LEDs exhibit small leak current and low turn-on voltage, with EQE 20 times higher than that of poly-LEDs $(0.04 \%)$.

\section{Sequential deposition method}

The sequential deposition is another choice for $2 \mathrm{D}$ perovskite films preparation, including sequential dipping process and sequential spin-coating $[9,13]$. The dipping process was employed to fabricate quasi- $2 \mathrm{D}$ and quasi-3D perovskite films [13]. The procedures of dipping process are given in Fig. 11a: spin-coating $\left(\mathrm{IC}_{2} \mathrm{H}_{4} \mathrm{NH}_{3}\right)_{2} \mathrm{PbI}_{4}$ layers on $\mathrm{mp}-\mathrm{TiO}_{2}$ substrates; immersing the films into MAI solution with a certain concentration for different dipping time (1-5 $\mathrm{min}$ ), and transferring the films into cleaning fluid ( $2 \mathrm{~mL}$ isopropanol mixed with $10 \mathrm{~mL}$ methylbenzene) to remove the MAI residual. With increasing dipping time, $\mathrm{MA}^{+}$cations in solution permeate into $\left(\mathrm{IC}_{2} \mathrm{H}_{4} \mathrm{NH}_{3}\right)_{2} \mathrm{PbI}_{4}$ films and consequently increase the thickness of inorganic $\mathrm{PbI}_{4}$ layers. Then, the nanoparticles gradually grow up and interconnect with each other in film morphology, leading to sharper diffraction peaks (Fig. 11b-d). The controlling over dipping time leads to sufficient contact of the reactants and therefore 

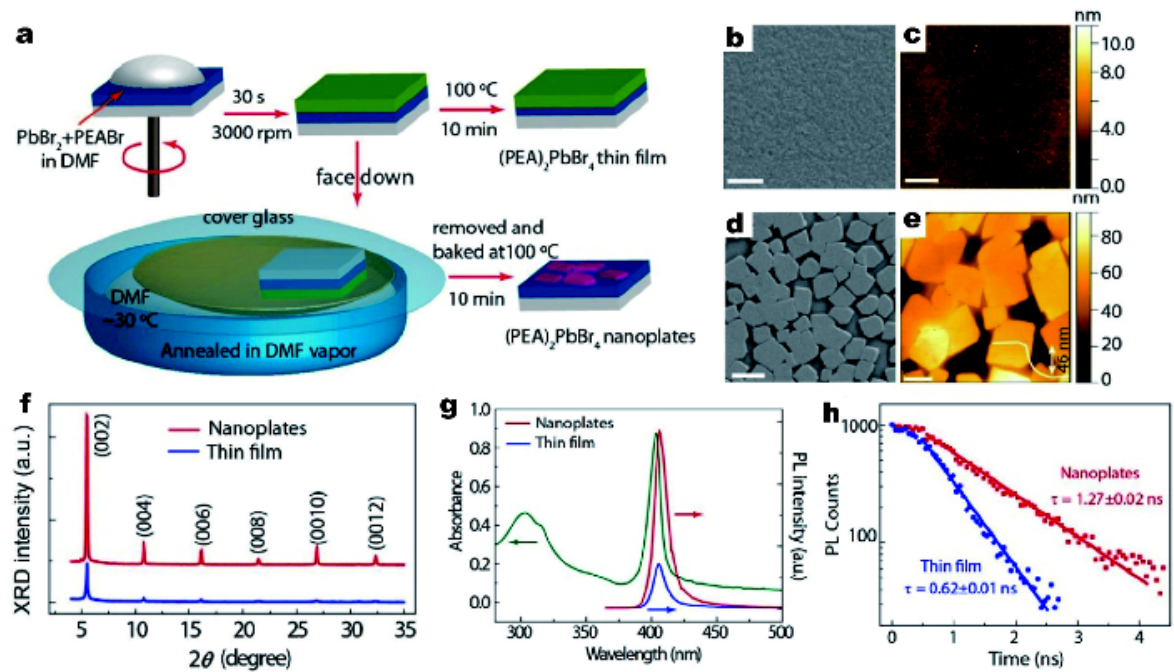

Figure 10 (a) The procedures of solution vapour annealing method. (b, d) SEM images, (c, e) AFM images, (f) XRD spectra, (g) absorption and PL spectra, (h) TRPL spectra of the nanosheets and polycrystalline films with or without the solution vapour annealing method [81]. Reprinted with permission from Ref. [81], Copyright 2016, American Chemical Society.
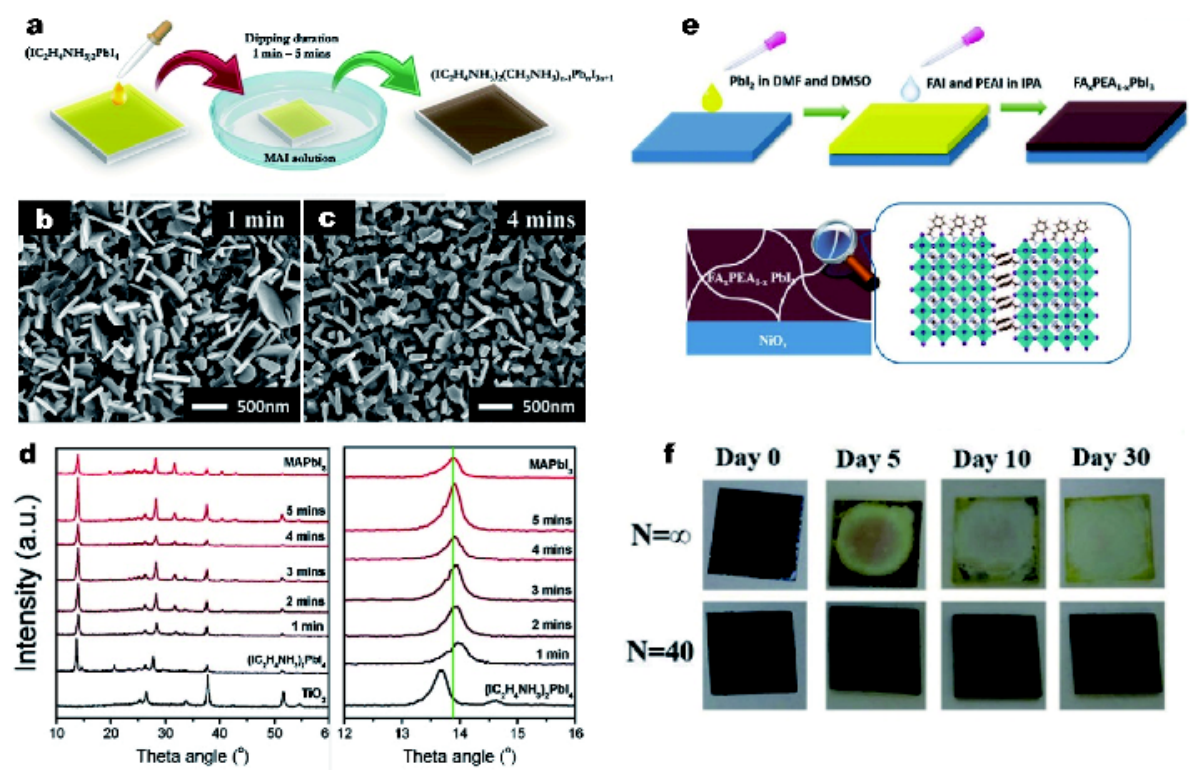

Figure 11 (a) The procedures of $\left(\mathrm{IC}_{2} \mathrm{H}_{4} \mathrm{NH}_{3}\right)_{2}\left(\mathrm{CH}_{3} \mathrm{NH}_{3}\right)_{n-1} \mathrm{~Pb}_{n} \mathrm{I}_{3 n+1}$ films prepared by dipping method. (b, c) The FESEM and (d) XRD spectra of $\left(\mathrm{IC}_{2} \mathrm{H}_{4} \mathrm{NH}_{3}\right)_{2}\left(\mathrm{CH}_{3} \mathrm{NH}_{3}\right)_{n-1} \mathrm{~Pb}_{n} \mathrm{I}_{3 n+1}$ films with different dipping time [13]. (e) The procedures of $\mathrm{FA}_{x} \mathrm{PEA}_{1-x} \mathrm{PbI}_{3}$ films prepared by the sequential deposition method and the structure diagram of $\mathrm{FA}_{x} \mathrm{PEA}_{1-x} \mathrm{PbI}_{3}$ quasi-3D perovskite crystal. (f) The photographs of $n=\infty$ and $n=40$ ( $n=\mathrm{FA} / \mathrm{PEA}$ ) films during the 30 days storage in ambient condition with a relative humidity of $40 \pm 5 \%$ [9]. Reprinted with permission from Ref. [13], Copyright 2016, Wiley-VCH Verlag GmBH\&Co. and Ref. [9], Copyright 2016, Wiley-VCH Verlag GmBH\&Co..

uniform films without residuals. In addition to this method, the ITO/ $\mathrm{NiO}_{x} /$ mixed-dimensional perovskite/ $\mathrm{PCBM} / \mathrm{bis}-\mathrm{C}_{60} / \mathrm{Ag}$ devices were prepared using the sequential spin-coating method with mixed-cations perovskite $\mathrm{FA}_{x} \mathrm{PEA}_{1-x} \mathrm{PbI}_{3}$ as the active layer [9]. To fabricate this perovskite film, a $\mathrm{PbI}_{2}$ layer was spin-coated on $\mathrm{NiO}_{x}$ substrate, followed by the $\mathrm{PEA}_{x} \mathrm{FA}_{1-x} \mathrm{I}$ solution loaded on it for $15 \mathrm{~s}$ before spin-coating. After thermal treatment, the mixed-cations $\mathrm{FA}_{x} \mathrm{PEA}_{1-x} \mathrm{PbI}_{3}$ perovskite films were finally formed. In this process, $\mathrm{PEA}^{+}$cations migrate to lattice surfaces and grain boundaries of $3 \mathrm{D}$ perovskite $\mathrm{FAPbI}_{3}$ to form quasi-3D rather than quasi-2D perovskite 
at room temperature, as shown in Fig. 11e. This selfassembly organic shell can prevent perovskite crystals from ambient moisture and passivate the surface defects to enhance the device performance. It is indicated by the theoretical calculation that the transition energy from black phase to yellow phase is raised, resulting in the enhanced phase stability of this quasi-3D perovskite (Fig. 11f).

In summay, the $2 \mathrm{D}$ perovskite films are generally fabricated using one-step spin-coating method because of its simple process and low cost, involving various phenomena and strategies. The small- $n$ members of $2 \mathrm{D}$ perovskite films have better film-formation compared with $3 \mathrm{D}$ counterpart. As $n$ increasing, pre- or posttreatment is necessary such as hot-cast, antisolvent or solution vapour annealing processes for better crystallization. Beside one-step spin-coating, sequential deposition also works for certain 2D perovskites. Sequential dipping method is used to grow perovskite films with the dimensions from pure-2D to $3 \mathrm{D}$ by changing dipping time. With this method, 2D perovskite crystals with an orientation vertical to the substrate can be obtained for efficient charge collection and extraction. Sequential spincoating is also considered as a method to prepare dense and uniform films due to the superior $\mathrm{PbI}_{2}$ framework for crystal growth. In sequential spin-coating, the large cations are not likely to enter into the lattice but pack on the surface of $3 \mathrm{D}$ perovskite grains, forming quasi-3D structure.

As a trend for $2 \mathrm{D}$ perovskite related research, the regulation of growth orientation and multiple phase are supposed to be considered, which are sensitive to raw material ratio and preparation condition. The distribution of different phases and the vertical growth orientation should also be engineered from crystallization kinetics for favourable device performance. For future large-scale fabrication, solution process is not enough for high-quality films in industrial producing. Instead, doctor blading, pressure-processing method and so on are more appropriate as long as high-quality crystal is obtained.

\section{APPLICATIONS OF 2D PEROVSKITE IN SOLAR CELLS AND LIGHT-EMITTING DIODES}

At present, 2D perovskite has been successfully applied in the optoelectronic fields, especially solar cells (SCs) and light emitting diodes (LEDs). Previous researches about $3 \mathrm{D}$ perovskite in material theories and device techniques create the foundation for the progress of $2 \mathrm{D}$ perovskite. This material is expected to prepare low-cost, large-scale, flexible and stable optoelectronics.

\section{Applications of 2D perovskite in solar cells}

In recent years, the organic-inorganic hybrid perovskite solar cells (PeSCs) have drawn great attention as one of the most promising solar cells. However, the Achilles heel of PeSCs is their stability resisting high temperature, illumination and humidity. Through ETL or HTL property improvement [82-86], interfaces engineering [87-89] and active layer modification [90], the device stability can be improved. Utilizing $2 \mathrm{D}$ perovskite as the photoactive layer offers a strategy for stable solar cells with simple spin-coating process. The hydrophobic organic layers prevent perovskite crystals from ambient moisture favouring improved device stability. Furthermore, 2D perovskite films exhibit better film-forming property than 3D analogue in same preparation conditions [55], leading to small leakage current in electronic devices. Although the intercalated organic cations inhibit the charge transport, carefully controlling the vertical orientation of inorganic crystals could be helpful $[6,14-$ 16].

\section{$2 D$ perovskite as absorbing layer}

Table 2 summarises the device structures and performance parameters of 2D PeSCs. For the first time, researchers used $(\mathrm{PEA})_{2}(\mathrm{MA})_{2}\left[\mathrm{~Pb}_{3} \mathrm{I}_{10}\right]$ as absorption layer in solar cells and obtained devices with the best power conversion efficiency (PCE) of $4.73 \%$ and optimal opencircuit voltage $\left(V_{\mathrm{OC}}\right)$ of $1.21 \mathrm{~V}$ [79]. The stability of these 2D PeSCs against humidity is superior to the original $\mathrm{MAPbI}_{3}$ solar cells. However, their $J-V$ characteristics have a severe hysteresis and the test results are sensitive to the scanning speed [79]. Soon afterwards, butylammonium (BA), [6,14] iodoethylammo-nium, [13] and PEI [40] were employed as organic cations and worked in active layers on $\mathrm{TiO}_{2}$ or PEDOT:PSS substrates. The structures and specific parameters are listed in Table 2.

Fig. 12a shows the photoelectric characteristic of $\mathrm{PEA}_{2}(\mathrm{MA})_{n-1} \mathrm{~Pb}_{n} \mathrm{I}_{3 n+1}$ with $n$ changing from 6 to $\infty$ [49]. For lower- $n$ members, the poor charge transport ability (i.e., low charge mobility or strong radiation recombination) and the insufficient absorption at near-infrared portion are responsible for the poor PCE. For large- $n$ members, the bandgap almost no longer changes and the mobility is the main limiting factor for PCE. It is known that the detrimental factor of $3 \mathrm{D}$ perovskite is trap volume density other than mobility. As a result, the $2 \mathrm{D}$ devices can achieve higher PCE than 3D devices before the radiation recombination loss is intolerable. Higher 
Table 2 Device structures and performance parameters of 2D PeSCs

\begin{tabular}{|c|c|c|c|c|c|c|c|}
\hline 2D-perovskite materials & $\begin{array}{c}\text { Cell configuration } \\
\mathrm{FTO} / . . / \mathrm{Au}(\mathrm{ITO} / . . / \mathrm{Ag})\end{array}$ & $\begin{array}{c}J_{\mathrm{SC}} \\
{\left[\mathrm{mA} \mathrm{cm}{ }^{-2}\right]}\end{array}$ & $\begin{array}{l}V_{\mathrm{OC}} \\
{[\mathrm{V}]}\end{array}$ & $\begin{array}{l}\mathrm{FF} \\
{[\%]}\end{array}$ & $\begin{array}{l}\text { PCE } \\
{[\%]}\end{array}$ & Methods & Ref \\
\hline$(\mathrm{BA})_{2}(\mathrm{MA})_{2} \mathrm{~Pb}_{3} \mathrm{I}_{10}$ & $\begin{array}{c}\mathrm{TiO}_{2} / 2 \mathrm{D}-\mathrm{PVK} / \text { spiro- } \\
\text { OMeTAD }\end{array}$ & 9.42 & 0.93 & 0.46 & 4.02 & One-step & {$[14$} \\
\hline$(\mathrm{BA})_{2}(\mathrm{MA})_{3} \mathrm{~Pb}_{4} \mathrm{I}_{13}$ & $\begin{array}{c}\text { PEDOT:PSS/2D-PVK/ } \\
\text { PCBM }\end{array}$ & 16.76 & 1.01 & 0.74 & 12.52 & Hot-cast & [6] \\
\hline $\mathrm{BA}_{2} \mathrm{CsPb}_{2} \mathrm{I}_{7}$ & $\begin{array}{c}\mathrm{TiO}_{2} / 2 \mathrm{D}-\mathrm{PVK} / \text { spiro- } \\
\text { OMeTAD }\end{array}$ & 8.88 & 0.96 & 57.0 & 4.84 & One-step & {$[91]$} \\
\hline $\mathrm{BA}_{2} \mathrm{MA}_{3} \mathrm{Sn}_{4} \mathrm{I}_{13}$ & $\mathrm{TiO}_{2} / 2 \mathrm{D}-\mathrm{PVK} / \mathrm{PTAA}$ & 24.1 & 0.23 & 45.7 & 2.53 & One-step & {$[92]$} \\
\hline$(\mathrm{PEA})_{2}(\mathrm{MA})_{2}\left[\mathrm{~Pb}_{3} \mathrm{I}_{10}\right]$ & $\begin{array}{l}\mathrm{TiO}_{2} / 2 \mathrm{D}-\mathrm{PVK} / \text { spiro- } \\
\text { OMeTAD }\end{array}$ & 6.72 & 1.18 & 0.60 & 4.73 & One-step & {$[79]$} \\
\hline$(\mathrm{PEA})_{2}(\mathrm{MA})_{n-1} \mathrm{~Pb}_{\mathrm{n}} \mathrm{I}_{3 n+1}^{\mathrm{a}}$ & $\begin{array}{c}\mathrm{TiO}_{2} / 2 \mathrm{D}-\mathrm{PVK} / \text { spiro- } \\
\text { OMeTAD }\end{array}$ & 19.12 & 1.09 & 0.74 & 15.36 & One-step & {$[49$} \\
\hline $\mathrm{FA}_{x} \mathrm{PEA}_{1-x} \mathrm{PbI}_{3}$ & $\begin{array}{c}\mathrm{NiO}_{x} / 2 \mathrm{D}-\mathrm{PVK} / \mathrm{PCBM} / \\
\text { BCP }\end{array}$ & 22.08 & 1.04 & 77.1 & 17.7 & Two-step & [9] \\
\hline \multirow[t]{2}{*}{$(\mathrm{PEA})_{2}(\mathrm{MA})_{n-1} \mathrm{~Pb}_{n} \mathrm{Br}_{3 n+1}$} & $\begin{array}{c}\mathrm{TiO}_{2} / 2 \mathrm{D}-\mathrm{PVK} / \text { spiro- } \\
\text { OMeTAD }\end{array}$ & 9.0 & 1.46 & 65 & 8.5 & \multirow[t]{2}{*}{ One-step } & \multirow[t]{2}{*}{93} \\
\hline & $\mathrm{TiO}_{2} / 2 \mathrm{D}-\mathrm{PVK}$ & 8.2 & 1.25 & 62 & 6.3 & & \\
\hline$(\mathrm{CA})_{2}(\mathrm{MA})_{n-1} \mathrm{~Pb}_{n} \mathrm{I}_{3 n+1}^{\mathrm{b}}$ & $\begin{array}{c}\mathrm{TiO}_{2} / 2 \mathrm{D}-\mathrm{PVK} / \text { spiro- } \\
\text { OMeTAD }\end{array}$ & 14.88 & 0.88 & 0.69 & 9.03 & Dipping & {$[13]$} \\
\hline$(\mathrm{PEI})_{2}(\mathrm{MA})_{6} \mathrm{~Pb}_{7} \mathrm{I}_{22}$ & $\begin{array}{c}\text { PEDOT:PSS/2D-PVK/ } \\
\text { PCBM }\end{array}$ & 13.12 & 1.10 & 0.65 & 10.08 & One-step & {$[40]$} \\
\hline \multirow[t]{2}{*}{$\left(\mathrm{AVAI} / \mathrm{PbI}_{2}\right) /\left(\mathrm{MAI} / \mathrm{PbI}_{2}\right)^{\mathrm{c}}$} & $\begin{array}{c}\mathrm{TiO}_{2} / 2 \mathrm{D}-\mathrm{PVK} / \text { spiro- } \\
\text { OMeTAD }\end{array}$ & 18.84 & 1.025 & 75.5 & 14.6 & \multirow[t]{2}{*}{ One-step } & \multirow[t]{2}{*}[54]{} \\
\hline & $\mathrm{TiO}_{2} / 2 \mathrm{D}-\mathrm{PVK}$ & 23.60 & 0.857 & 58.7 & 11.9 & & \\
\hline $\mathrm{HA}_{2} \mathrm{MAPb}_{2} \mathrm{I}_{7}^{\mathrm{d}}$ & \multirow{3}{*}{$\begin{array}{l}\mathrm{TiO}_{2} / 2 \mathrm{D}-\mathrm{PVK} / \text { spiro- } \\
\text { OMeTAD }\end{array}$} & 1.33 & 0.71 & 35.5 & 0.34 & \multirow{3}{*}{ One-step } & \multirow{3}{*}{94} \\
\hline $\mathrm{HA}_{2} \mathrm{FAPb}_{2} \mathrm{I}_{7}$ & & 2.86 & 0.64 & 54.6 & 1.03 & & \\
\hline $\mathrm{HA}_{2} \mathrm{CsPb}_{2} \mathrm{I}_{7}$ & & 0.68 & 0.33 & 46.2 & 0.10 & & \\
\hline $\mathrm{MA}_{2} \mathrm{CuCl}_{2} \mathrm{Br}_{2}$ & $\begin{array}{c}\mathrm{TiO}_{2} / 2 \mathrm{D}-\mathrm{PVK} / \text { spiro- } \\
\text { OMeTAD }\end{array}$ & 0.216 & 0.256 & 0.32 & 0.017 & One-step & {$[80$} \\
\hline
\end{tabular}

a) $n=60$; b) $\mathrm{CA}=\mathrm{IC}_{2} \mathrm{H}_{4} \mathrm{NH}_{3}{ }^{+}, n$ is controlled by the dipping time $\left(2 \mathrm{mg} \mathrm{mL}{ }^{-1} \mathrm{MAI}\right.$ in isopropanol/methylbenzene=1/5); c) $(\mathrm{AVAI} / \mathrm{PbI})_{2}$ take up $3 \%$ of the total volume; d) $\mathrm{HA}=n-\mathrm{C}_{6} \mathrm{H}_{13} \mathrm{NH}_{3}^{+}$

$V_{\mathrm{OC}}$ of 2D PeSCs has been reported in many publications, and different mechanisms were put forward. However, it is a common view that the higher $V_{\mathrm{OC}}$ originates from lower mobility. Quan et al. [49] supposed that lower mobility leads to slower charge extraction, followed by carriers accumulation which enables higher $V_{\mathrm{OC}}$. Meanwhile, Cohen et al. [93] inferred that lower mobility of 2D perovskite relieves the carrier accumulation at selective contact, and therefore reduces the quenching at interface and results in higher $V_{\mathrm{OC}}$. The $V_{\mathrm{OC}}$ could potentially be further improved through transport materials selecting and contact interface engineering $[6,14]$.

Although the enhanced $V_{\mathrm{OC}}$ of 2D PeSCs was observed in many reports, the mainstream strategy for improving solar cell efficiency is to enlarge the $J_{\mathrm{SC}}$ and FF as possible, which requires large carrier mobilities of active layer. The charge transport of $2 \mathrm{D}$ perovskite can be improved by selecting large cation and regulating the vertical orientation for better efficiency. Yao et al. [40] compared the charge transport abilities of BA-based, PEI-based 2D perovskite and 3D perovskite using time-resolved PL and the time constant are $6.6,8.9$ and $11.8 \mathrm{~ns}$, respectively. This implies using polymeric ammonium presents a way of addressing the problems of poor charge transport in $2 \mathrm{D}$ perovskite. Otherwise, regulating the vertical growth of $2 \mathrm{D}$ perovskite is also desirable for good charge transport. Uniform and dense $(\mathrm{BA})_{2}(\mathrm{MA})_{n-1} \mathrm{~Pb}_{n} \mathrm{I}_{3 n+1}$ films can be grown in orientation by crude one-step method, while the $\mathrm{MAPbI}_{3}$ films exhibit rough morphology under the same condition [14]. The hot-cast method was used to grow near-single-crystal $(\mathrm{BA})_{2}(\mathrm{MA})_{3} \mathrm{~Pb}_{4} \mathrm{I}_{13}$ films with vertical orientation [6]. Although the efficiencies of low$n$-value 2D PeSCs gradually decrease as the proportion of large cation increases, the change of stability follows the 

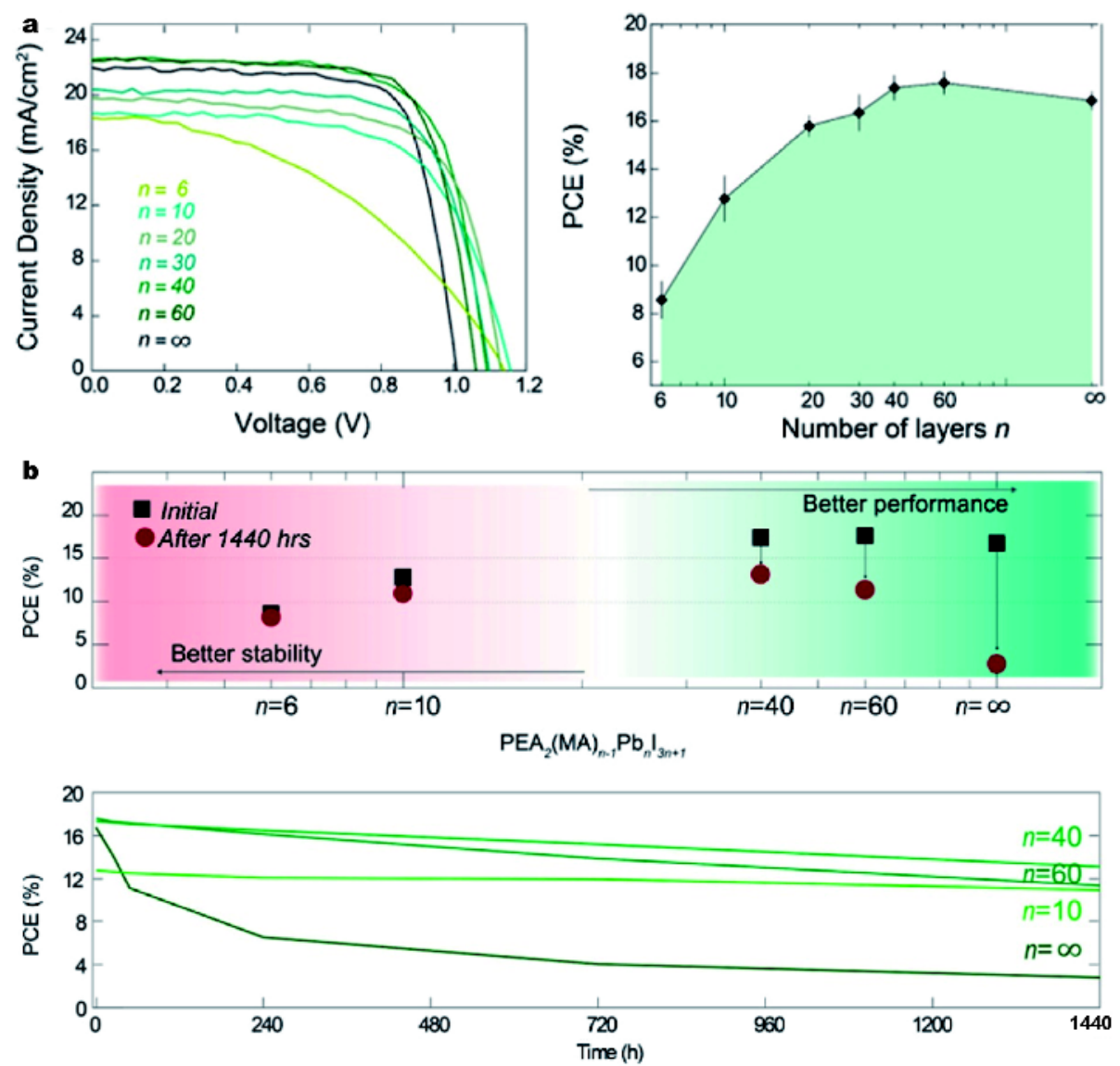

Figure 12 (a) The $J-V$ curves and PCE of $\mathrm{PEA}_{2}(\mathrm{MA})_{n-1} \mathrm{~Pb}_{n} \mathrm{I}_{3 n+1}$ with $n$ changing from 0 to $\infty$. (b) The trade-off between PCE and stability of $\mathrm{PEA}_{2} \mathrm{MA}_{n-1} \mathrm{~Pb}_{n} \mathrm{I}_{3 n+1}$ solar cells $(n=6,10,40,60$, and $\infty$ ) [49]. Reprinted with permission from Ref. [49], Copyright 2016, American Chemical Society.

opposite trend. As shown in Fig. 12b, there is a trade-off between the stability and efficiency. To obtain both higher PCE and stability than 3D devices, 2D perovskite with large $n$ is more suitable for application of solar cells.

It is worth mentioning that the high stability and good film-formation of 2D perovskite greatly favour the large-scale fabrication. Yao et al. [40] prepared the 2D PeSCs with a p-i-n structure of PEDOT:PSS/(PEI $)_{2}(\mathrm{MA})_{n-1} \mathrm{~Pb}_{n} \mathrm{I}_{3 n+1} /$ PCBM. The PCE of $2 \mathrm{D}$ devices $(10.08 \%$ when $n=7)$ are lower than those of $\mathrm{MAPbI}_{3}$ devices $(15.42 \%)$ in smallarea of $0.04 \mathrm{~cm}^{2}$. However, when the area is enlarged to $2.32 \mathrm{~cm}^{2}$, the $\mathrm{MAPbI}_{3}$ devices exhit a severe deterioration and show a PCE of $5.82 \%$. By contrast, the 2D PeSCs achieve the highest PCE of $8.77 \%$, remaining $90 \%$ of the original value after $500 \mathrm{~h}$ (AM 1.5G; $100 \mathrm{~mW} \mathrm{~cm}^{-2}$ ) without encapsulated. Grancini et al. [54] used $\left(\mathrm{AVAI} / \mathrm{PbI}_{2}\right) /\left(\mathrm{MAI} / \mathrm{PbI}_{2}\right)$ precursor solution to prepare $10 \times 10 \mathrm{~cm}^{2}$ devices by a fully printable process, and reported a PCE of $11.2 \%$ when $\left(\mathrm{AVAI} / \mathrm{PbI}_{2}\right)$ components take up $3 \%$ of the total volume. These PeSCs maintained long-term stability at AM 1.5G for at least 5,000 h.

\section{$2 D$ perovskite as modified layer}

Other cases are the utilizations of $2 \mathrm{D}$ perovskites as modified layers between absorption layer and transport layers for interface passivation [95-97]. A layer of $(\mathrm{PEI})_{2} \mathrm{PbI}_{4}$ between PEDOT:PSS and $\mathrm{MAPbI}_{3}$ acts as a growing template for micron-grain and favours the formation of homogeneous films. The HOMO level of $(\mathrm{PEI})_{2} \mathrm{PbI}_{4}(5.3 \mathrm{eV})$ matches well with the PEDOT:PSS and $3 \mathrm{D}$ perovskite which is beneficial to the holeinjection into the HTLs. Devices based on the FTO substrates and flexible substrates exhibit PCE of $>16 \%$ and $13.8 \%$ respectively under the same experimental conditions. The modified devices retained $90 \%$ of their initial PCE after continuous illumination for $200 \mathrm{~h}$. Wang et al. [96] spin-coated a layer of aniline (A), benzylamine (BA) or phenethylamine (PEA) on $\mathrm{FAPbI}_{3}$ as passivation layers. Although A, BA, and PEA all contain hydrophobic benzene ring in them, their modified devices have 
different levels of water-resistivity. The $\mathrm{BA}-\mathrm{FAPbI}_{3}$ shows much better stability than others for two reasons: (1) the calculated water adsorption energy of $\mathrm{BA}-\mathrm{FAPbI}_{3}$ is much reduced compared with $\mathrm{FAPbI}_{3}$ and $\mathrm{A}-\mathrm{FAPbI}_{3}$; (2) the distance between water molecules and $\mathrm{Pb}-\mathrm{I}$ is larger in $\mathrm{BA}-\mathrm{FAPbI}_{3}$ because of the perpendicular steric arrangement of BA molecules. Finally, they obtained devices with PCE $>19 \%$, remaining almost unchanged in the initial three days in the air $(50 \pm 5 \mathrm{RH} \%)$ and $50 \%$ of original PCE value after 4 months. It is worth mentioning that the PCE showed almost no decline after 4 months in the air if the spiro-OMeTAD layer and Au electrode were prepared right before tested. Furthermore, Cho et al. [97] selectively grew $2 \mathrm{D}$ perovskite on the surface of $\mathrm{Cs}_{0.1} \mathrm{FA}_{0.74} \mathrm{MA}_{0.13} \mathrm{PbI}_{2.48} \mathrm{Br}_{0.39}$ film by treating it with a PEAI isopropanol solution. This thin 2D perovskite layer blocks the transfer of electrons to HTL and reduces the charge recombination owing to energy band offset. The best PCE of $20.1 \%$ was obtained and it remained $85 \%$ in humid environment after the device stressed at $50^{\circ} \mathrm{C}$ under continuous illumination of full intensity for $800 \mathrm{~h}$.

\section{Applications of 2D perovskite in light-emitting diodes}

In addition to the application in solar cells, the organicinorganic perovskites are also promising in electroluminescence (EL) attributing to their high colour purity, tunable bandgap, low nonradiative recombination rates and good charge transport properties [98-102]. At present, the luminance of perovskite light-emitting diodes (PeLEDs) has exceeded $10,000 \mathrm{~cd} \mathrm{~m}^{-2}[103,104]$. Xing et al. [105] have prepared LED devices employing $\mathrm{CH}_{3} \mathrm{NH}_{3} \mathrm{PbBr}_{3}$ amorphous nanoparticles as emitting material with the best current efficiency (CE) of $11.49 \mathrm{~cd} \mathrm{~A}^{-1}$, luminous efficiency of $7.84 \mathrm{~lm} \mathrm{~W}^{-1}$, and EQE of 3.8\%. Besides, 3D-PeLEDs benefit from high colour tunability achieved by various ratios of halogen ingredients, together with low preparation cost from solution process. However, the performance of 3DPeLEDs is somehow limited. 3D perovskites have small exciton binding energy and long exciton diffusion length. As a result, excitons are dissociated into carriers easily and quenched by defects, which impedes radiative recombination and limits EL efficiency. The natural limits of 3D perovskite can be unrestricted by quantum confinement. By reducing the grain size, the exciton diffusion length is decreased, which inhibits the dissociation of excitons and improves device performance [98]. However, the electroluminescence quantum yield (ELQY) of 3D-PeLEDs is still far lower than the theoretical maximum PLQE of $70 \%$. The main reasons include current loss from incomplete coverage of substrate, high working voltage from barriers to electron injection, and inevitable high excitation intensity for high PLQE [99].

It is well-known that the emitting-layers of LEDs are typically thin to confine the injected carriers and maximise charge density [99]. However, thin films usually have pinholes and show coverage incompletely on substrates, leading to moderate EQE $[100,103]$. Further solutions are found in dimension-reduction of perovskite, where the excitons are confined by the organic layers, resulting in improved radiative recombination efficiency [81]. Furthermore, the 2D perovskite has good filmforming properties compared with 3D analogue $[12,55]$. These excellent exciton and film-forming properties of 2D perovskite bring about an enhanced PLQE and remarkable EQE of $14.36 \%$ [106]. Particularly, although the pure-2D 2D-perovskites have good film-forming properties (like in quasi-2D ones) [107], the excitons in them quench rapidly regarding nonradiative recombination, resulting in low PLQEs $[59,108]$. Therefore most impressive performances of $2 \mathrm{D}$ perovskite LED are from quasi-2D perovskite rather than pure-2D one. In recent years, blue, green and near-infrared (NIR) 2D PeLEDs have already been reported. Table 3 demonstrates different structures and performance parameters of several 2D-PeLEDs. The $2 \mathrm{D}$ perovskite is also used in broadband single-source white-light emitters, achieving the highest colour rendering index (CRI) of 85 , which is an approach to the high CRI value of mixed-phosphor light sources [47]. Further breakthroughs of 2D PeLEDs are possible focused on organic materials design, defectsfree films techniques as well as the crystallising process influenced by various types of organic cations. Besides, although blue 2D PeLEDs have been reported, their performance still has great potential to be improved.

In comparison, the significantly higher emitting efficiency of quasi-2D perovskite than $3 \mathrm{D}$ counterpart is due to the exciton confinement effect of self-organized MQWs [11]. With the better confinement of exciton in inorganic sheets, the binding energy of perovskite can be effectively raised from tens of $\mathrm{eV}$ up to hundreds of $\mathrm{eV}$ by introducing 2D configuration [59,61].The strongly bound excitons in $2 \mathrm{D}$ perovskite generally go through faster radiative recombination compared with in $3 \mathrm{D}$ one. Together with shorter diffusion length, excitons are less possible to be quenched by defects on grain boundaries and film interfaces, which ultimately leads to relatively higher PLQE in quasi-2D perovskite. By far, impressive PLQY (more than 70\%) and EQE of LED device (more than $14 \%$ ) have been achieved with quasi-2D perovskite, 
Table 3 Device structures and performance parameters of several 2D PeLEDs

\begin{tabular}{|c|c|c|c|c|c|c|c|c|}
\hline 2D-perovskite materials & $\begin{array}{l}\text { Cell configuration } \\
\text { ITO/ }\end{array}$ & $\begin{array}{c}\mathrm{CE} \\
{\left[\mathrm{cd} \mathrm{A} \mathrm{A}^{-1}\right]}\end{array}$ & $\begin{array}{c}L_{\max } \\
{\left[\mathrm{cd} \mathrm{m}^{-2}\right]}\end{array}$ & $\begin{array}{c}V_{\mathrm{t}} \\
{[\mathrm{V}]}\end{array}$ & $\begin{array}{l}\text { EQE } \\
{[\%]}\end{array}$ & $\begin{array}{c}\text { PLQE } \\
{[\%]}\end{array}$ & $\begin{array}{c}\mathrm{EL} \\
(\mathrm{nm})\end{array}$ & Ref. \\
\hline$\left(\mathrm{PEA}^{\mathrm{a}}\right)_{2}\left[\mathrm{PbI}_{4}\right]$ & $\begin{array}{c}\text { 2D perovskite/OXD7 } / \\
\text { MgAg }\end{array}$ & l & 10000 & 24 & / & / & 520 & [109] \\
\hline$(\mathrm{PEA})_{2} \mathrm{PbBr}_{4}$ & $\begin{array}{c}\text { PEDOT:PSS/2D perovs- } \\
\text { kite/TPBi/Ca/Al }\end{array}$ & l & I & 2.5 & 0.04 & 26 & 410 & {$[81]$} \\
\hline$(\mathrm{PEA})_{2}(\mathrm{MA})_{n-1} \mathrm{~Pb}_{n} \mathrm{Br}_{3 n+1}{ }^{\mathrm{c}}$ & $\begin{array}{c}\text { Buf-HIL }{ }^{\mathrm{d}} / 2 \mathrm{D} \text { perovskite/ } \\
\text { TPBi/Al }\end{array}$ & 4.9 & 2935 & l & l & 34 & 520 & {$[55]$} \\
\hline$(\mathrm{PEA})_{2}(\mathrm{MA})_{n-1} \mathrm{~Pb}_{n} \mathrm{Br}_{3 n+1}^{\mathrm{e}}$ & $\begin{array}{c}\mathrm{TiO}_{2} / 2 \mathrm{D} \text { perovskite/F8/ } \\
\mathrm{MoO}_{3} / \mathrm{Au}\end{array}$ & l & $(80)^{\mathrm{f}}$ & 7.4 & 8.8 & 10.6 & 760 & {$[12]$} \\
\hline $\mathrm{PEA}_{2}\left(\mathrm{FAPbBr}_{3}\right)_{n-1} \mathrm{PbBr}_{4}^{\mathrm{g}}$ & $\begin{array}{c}\text { m-PEDOT:PSS/2D-per- } \\
\text { ovskite/TOPO/TPBi/ } \\
\text { LiF/Al }\end{array}$ & 62.43 & 9120 & 2.8 & 14.36 & 73.8 & 532 & {$[106]$} \\
\hline$\left(\mathrm{NMA}^{\mathrm{h}}\right)_{2}(\mathrm{FA}) \mathrm{Pb}_{2} \mathrm{I}_{7}$ & \multirow{2}{*}{$\begin{array}{l}\mathrm{ZnO}(\mathrm{PEIE}) / 2 \mathrm{D} \text { perovs- } \\
\text { kite/TFB/MoO } / \mathrm{Au}\end{array}$} & l & $(55)^{6}$ & 1.5 & 9.6 & 60 & 786 & \multirow{2}{*}[11]{} \\
\hline$(\mathrm{NMA})_{2}(\mathrm{FA}) \mathrm{Pb}_{2} \mathrm{I}_{6} \mathrm{Br}$ & & I & $(82)^{6}$ & 1.3 & 11.7 & 67 & 763 & \\
\hline
\end{tabular}

a) Working at temperature of liquid nitrogen; b) OXD7 is an oxadiazole derivative; c) MA:PEA=1:6; d) Buf-HIL solution: (poly(3,4-ethyle nedioxythiophene)/poly(styrene sulfonate)/perfluorinated ionomer $=1 / 6 / 25.4(w / w / w))$; e) $n=5 ;$ f) Radiance, unit of measurement $\left[\mathrm{W} \mathrm{Sr}^{-1} \mathrm{~m}^{-2}\right]$; g) $n=3$; h) NMAI=1-naphthylmethylamine iodide $\left(\mathrm{C}_{10} \mathrm{H}_{7} \mathrm{CH}_{2} \mathrm{NH}_{3}{ }^{+}\right)$.

which are higher than those of any other 3D perovskite, as recently reported [106].

By far the EQEs of 2D perovskite LED have exceeded those of $3 \mathrm{D}$ ones in red and green colours $[12,106]$. However, the performances of blue 2D perovskite still remain moderate [81]. The low efficiency in both $2 \mathrm{D}$ and $3 \mathrm{D}$ blue perovskite is mainly caused by the difficulty of introducing chloride precursor for its low solubility in regularly used solvents (e.g., $\mathrm{N}, \mathrm{N}$-dimethylformamide). Therefore, the most feasible way to blue emission is to introduce 2D configuration in bromine-based perovskite, and thus the blue-shift effect due to quantum confinement would lead to blue emission. However, enough blue-shift effect (for emission below $450 \mathrm{~nm}$ ) can only be attained in pure-2D perovskite, in which some unknown superfast [55] phonon-mediated thermal quenching [52] mechanism would intensively quench excitons. The details of this mechanism still remain unclear, but the future thoroughly understanding of it is supposed to be favourable for getting efficient blue emission from perovskite and accomplishing full-colour emission.

\section{CONCLUSION}

This review gives a generalisation of 2D perovskite from material characteristics to optoelectronics applications. First, we introduced the structure and typical properties of $2 \mathrm{D}$ perovskite, including the stability, quantum confinement effect and exciton properties, multiple phases and preferred orientation in $2 \mathrm{D}$ perovskite. Second, we described and compared the preparation technologies of 2D perovskite films. Then, the application status in the field of solar cells and light-emitting diodes is summarized. For 2D PeSCs, devices with higher efficiency and stability than 3D ones can be obtained by the incorporation of small doses of large ammonium in absorbing layer or at the interface with transport layers. The 2D-PeLEDs can achieve better performance than 3D analogue due to the quantum confinement effect as well as enhanced stability, implying that $2 \mathrm{D}$ perovskite is suitable as light-emitting materials. The high stability and good film-forming of $2 \mathrm{D}$ perovskite greatly favour the large-scale industrialized fabrication.

There exist some challenges at the same time. It is significant to design appropriate organic cations with remarkable properties, such as using small organics with strong charge transfer ability to improve the conductivity. The mechanism of the formation and distribution of the multiple phases in 2D perovskite is not so clear (for example, why multiple phases appear in some $2 \mathrm{D}$ perovskite but are not so obvious in others?). The influence of the ratio and distribution of different phases on device performance are accordingly necessary to be explored. Furthermore, there is no specific conclusion about the poor quantum yield of pure-2D perovskite which has considerable quantum confinement effect/ exciton binding energy (how are the excitons quenched?). The preparation processes of $2 \mathrm{D}$ perovskite need to be engineered for improved devices performance. Low-cost and low-temperature preparation techniques for highquality and large-area 2D perovskite films could make great sense in the future. In a word, there are still many challenges in this filed and further promotion is expected 
to be achieved.

Received 26 March 2018; accepted 3 May 2018; published online 5 July 2018

1 Weber D. $\mathrm{CH}_{3} \mathrm{NH}_{3} \mathrm{SnBr}_{x} \mathrm{I}_{3-x}(x=0-3)$, ein $\mathrm{Sn}(\mathrm{II})$-System mit kubischer Perowskitstruktur/ $\mathrm{CH}_{3} \mathrm{NH}_{3} \mathrm{SnBr}_{x} \mathrm{I}_{3-x}(x=0-3)$, a $\mathrm{Sn}(\mathrm{II})-$ system with cubic perovskite structure. Zeitschrift für Naturforschung B, 1978, 33: 862-865

2 Weber D. $\mathrm{CH}_{3} \mathrm{NH}_{3} \mathrm{PbX}_{3}$, ein $\mathrm{Pb}$ (II)-System mit kubischer Perowskitstruktur/ $\mathrm{CH}_{3} \mathrm{NH}_{3} \mathrm{PbX}_{3}$, a $\mathrm{Pb}$ (II)-System with cubic perovskite structure. Zeitschrift für Naturforschung B, 1978, 33: 1443-1445

3 Li M, Wang $\mathrm{ZK}$, Zhuo MP, et al. $\mathrm{Pb}-\mathrm{Sn}-\mathrm{Cu}$ ternary organometallic halide perovskite solar cells. Adv Mater, 2018, 131: 1800258

4 Wang ZK, Li M, Yang YG, et al. High efficiency Pb-In binary metal perovskite solar cells. Adv Mater, 2016, 28: 6695-6703

5 Sun S, Salim T, Mathews N, et al. The origin of high efficiency in low-temperature solution-processable bilayer organometal halide hybrid solar cells. Energy Environ Sci, 2014, 7: 399-407

6 Tsai H, Nie W, Blancon JC, et al. High-efficiency two-dimensional Ruddlesden-Popper perovskite solar cells. Nature, 2016, 536: $312-316$

7 Lim KG, Kim HB, Jeong J, et al. Boosting the power conversion efficiency of perovskite solar cells using self-organized polymeric hole extraction layers with high work function. Adv Mater, 2014, 26: 6461-6466

8 Tyagi P, Arveson SM, Tisdale WA. Colloidal organohalide perovskite nanoplatelets exhibiting quantum confinement. J Phys Chem Lett, 2015, 6: 1911-1916

9 Li N, Zhu Z, Chueh CC, et al. Mixed cation $\mathrm{FA}_{x} \mathrm{PEA}_{1-x} \mathrm{PbI}_{3}$ with enhanced phase and ambient stability toward high-performance perovskite solar cells. Adv Energy Mater, 2017, 7: 1601307

10 Saparov B, Mitzi DB. Organic-inorganic perovskites: structural versatility for functional materials design. Chem Rev, 2016, 116: 4558-4596

11 Wang N, Cheng L, Ge R, et al. Perovskite light-emitting diodes based on solution-processed self-organized multiple quantum wells. Nat Photonics, 2016, 10: 699-704

12 Yuan M, Quan LN, Comin R, et al. Perovskite energy funnels for efficient light-emitting diodes. Nat Nanotechnol, 2016, 11: 872877

13 Koh TM, Shanmugam V, Schlipf J, et al. Nanostructuring mixeddimensional perovskites: a route toward tunable, efficient photovoltaics. Adv Mater, 2016, 28: 3653-3661

14 Cao DH, Stoumpos CC, Farha OK, et al. 2D homologous perovskites as light-absorbing materials for solar cell applications. J Am Chem Soc, 2015, 137: 7843-7850

$15 \mathrm{Hu} \mathrm{H}$, Salim T, Chen B, et al. Molecularly engineered organicinorganic hybrid perovskite with multiple quantum well structure for multicolored light-emitting diodes. Sci Rep, 2016, 6: 33546

16 Milot RL, Sutton RJ, Eperon GE, et al. Charge-carrier dynamics in 2D hybrid metal-halide perovskites. Nano Lett, 2016, 16: 70017007

17 Xing G, Mathews N, Sun S, et al. Long-range balanced electronand hole-transport lengths in organic-inorganic $\mathrm{CH}_{3} \mathrm{NH}_{3} \mathrm{PbI}_{3}$. Science, 2013, 342: 344-347

18 Eperon GE, Burlakov VM, Docampo P, et al. Morphological control for high performance, solution-processed planar hetero- junction perovskite solar cells. Adv Funct Mater, 2014, 24: 151157

19 Docampo P, Ball JM, Darwich M, et al. Efficient organometal trihalide perovskite planar-heterojunction solar cells on flexible polymer substrates. Nat Commun, 2013, 4: 2761

20 Liang PW, Liao CY, Chueh CC, et al. Additive enhanced crystallization of solution-processed perovskite for highly efficient planar-heterojunction solar cells. Adv Mater, 2014, 26: 3748-3754

21 Xue $\mathrm{M}$, Zhou $\mathrm{H}, \mathrm{Xu} \mathrm{Y}$, et al. High-performance ultraviolet-visible tunable perovskite photodetector based on solar cell structure. Sci China Mater, 2017, 60: 407-414

22 Ding J, Yan Q. Progress in organic-inorganic hybrid halide perovskite single crystal: growth techniques and applications. Sci China Mater, 2017, 60: 1063-1078

23 Ren Y, Duan B, Xu Y, et al. New insight into solvent engineering technology from evolution of intermediates via one-step spincoating approach. Sci China Mater, 2017, 60: 392-398

24 Pascoe AR, Gu Q, Rothmann MU, et al. Directing nucleation and growth kinetics in solution-processed hybrid perovskite thinfilms. Sci China Mater, 2017, 60: 617-628

25 Deng Y, Peng E, Shao Y, et al. Scalable fabrication of efficient organolead trihalide perovskite solar cells with doctor-bladed active layers. Energy Environ Sci, 2015, 8: 1544-1550

26 Barrows AT, Pearson AJ, Kwak CK, et al. Efficient planar heterojunction mixed-halide perovskite solar cells deposited via spray-deposition. Energy Environ Sci, 2014, 7: 2944-2950

27 Chen $\mathrm{H}, \mathrm{Ye}$ F, Tang W, et al. A solvent- and vacuum-free route to large-area perovskite films for efficient solar modules. Nature, 2017, 131: 92-95

28 Ye F, Tang W, Xie F, et al. Low-temperature soft-cover deposition of uniform large-scale perovskite films for high-performance solar cells. Adv Mater, 2017, 29: 1701440

29 Kind R. Structural phase transitions in perovskite layer structures. Ferroelectrics, 1980, 24: 81-88

30 Arend $\mathrm{H}$, Huber W, Mischgofsky FH, et al. Layer perovskites of the $\left(\mathrm{C}_{n} \mathrm{H}_{2 n+1} \mathrm{NH}_{3}\right)_{2} \mathrm{MX}_{4}$ and $\mathrm{NH}_{3}\left(\mathrm{CH}_{2}\right)_{m} \mathrm{NH}_{3} \mathrm{MX}_{4}$ families with $\mathrm{M}$ $=\mathrm{Cd}, \mathrm{Cu}, \mathrm{Fe}, \mathrm{Mn}$ or $\mathrm{Pd}$ and $\mathrm{X}=\mathrm{Cl}$ or Br: Importance, solubilities and simple growth techniques. J Cryst Growth, 1978, 43: 213-223

31 Swetha T, Singh SP. Perovskite solar cells based on small molecule hole transporting materials. J Mater Chem A, 2015, 3: 1832918344

32 Ishihara $\mathrm{T}$, Takahashi J, Goto T. Exciton state in two-dimensional perovskite semiconductor $\left(\mathrm{C}_{10} \mathrm{H}_{21} \mathrm{NH}_{3}\right)_{2} \mathrm{PbI}_{4}$. Solid State Commun, 1989, 69: 933-936

33 Ishihara T, Takahashi J, Goto T. Optical properties due to electronic transitions in two-dimensional semiconductors $\left(\mathrm{C}_{n} \mathrm{H}_{2 n+1} \mathrm{NH}_{3}\right)_{2} \mathrm{PbI}_{4}$. Phys Rev B, 1990, 42: 11099-11107

34 Calabrese J, Jones NL, Harlow RL, et al. Preparation and characterization of layered lead halide compounds. J Am Chem Soc, 1991, 113: 2328-2330

35 Mitzi DB, Feild CA, Harrison WTA, et al. Conducting tin halides with a layered organic-based perovskite structure. Nature, 1994, 369: 467-469

36 Papavassiliou GC, Koutselas IB. Structural, optical and related properties of some natural three- and lower-dimensional semiconductor systems. Synth Met, 1995, 71: 1713-1714

37 Mitzi DB, Chondroudis K, Kagan CR. Design, structure, and optical properties of organic-inorganic perovskites containing an oligothiophene chromophore. Inorg Chem, 1999, 38: 6246-6256 38 Cheng Z, Lin J. Layered organic-inorganic hybrid perovskites: 
structure, optical properties, film preparation, patterning and templating engineering. CrystEngComm, 2010, 12: 2646-2662

39 Huang TJ, Thiang ZX, Yin X, et al. $\left(\mathrm{CH}_{3} \mathrm{NH}_{3}\right)_{2} \mathrm{PdCl}_{4}$ : A compound with two-dimensional organic-inorganic layered perovskite structure. Chem Eur J, 2016, 22: 2146-2152

40 Yao K, Wang X, Xu Y, et al. Multilayered perovskite materials based on polymeric-ammonium cations for stable large-area solar cell. Chem Mater, 2016, 28: 3131-3138

41 Kawano N, Koshimizu M, Sun Y, et al. Effects of organic moieties on luminescence properties of organic-inorganic layered perovskite-type compounds. J Phys Chem C, 2014, 118: 9101-9106

42 Kitazawa N, Watanabe Y. Optical properties of natural quantumwell compounds $\left(\mathrm{C}_{6} \mathrm{H}_{5}-\mathrm{C}_{n} \mathrm{H}_{2 n}-\mathrm{NH}_{3}\right)_{2} \mathrm{PbBr}_{4}(n=1-4)$. J Phys Chem Solids, 2010, 71: 797-802

43 Even J, Pedesseau L, Katan C. Understanding quantum confinement of charge carriers in layered 2D hybrid perovskites. ChemPhysChem, 2014, 15: 3733-3741

44 Chong WK, Thirumal K, Giovanni D, et al. Dominant factors limiting the optical gain in layered two-dimensional halide perovskite thin films. Phys Chem Chem Phys, 2016, 18: 14701-14708

45 Kamminga ME, Fang HH, Filip MR, et al. Confinement effects in low-dimensional lead iodide perovskite hybrids. Chem Mater, 2016, 28: 4554-4562

46 Mitzi DB, Wang S, Feild CA, et al. Conducting layered organicinorganic halides containing (110)-oriented perovskite sheets. Science, 1995, 267: 1473-1476

47 Mitzi DB. Solution-processed inorganic semiconductors. J Mater Chem, 2004, 14: 2355-2365

48 Mitzi DB, Medeiros DR, Malenfant PRL. Intercalated organicinorganic perovskites stabilized by fluoroaryl-aryl interactions. Inorg Chem, 2002, 41: 2134-2145

49 Quan LN, Yuan M, Comin R, et al. Ligand-stabilized reduceddimensionality perovskites. J Am Chem Soc, 2016, 138: 26492655

50 Lin Y, Bai Y, Fang Y, et al. Suppressed ion migration in lowdimensional perovskites. ACS Energy Lett, 2017, 2: 1571-1572

51 Cai B, Li X, Gu Y, et al. Quantum confinement effect of twodimensional all-inorganic halide perovskites. Sci China Mater, 2017, 60: 811-818

52 Dou L, Wong AB, Yu Y, et al. Atomically thin two-dimensional organic-inorganic hybrid perovskites. Science, 2015, 349: 15181521

53 Ishihara T. Optical properties of PbI-based perovskite structures. J Lumin, 1994, 60-61: 269-274

54 Grancini G, Roldán-Carmona C, Zimmermann I, et al. One-Year stable perovskite solar cells by $2 \mathrm{D} / 3 \mathrm{D}$ interface engineering. Nat Commun, 2017, 8: 15684

55 Byun J, Cho $\mathrm{H}$, Wolf $\mathrm{C}$, et al. Efficient visible quasi-2D perovskite light-emitting diodes. Adv Mater, 2016, 28: 7515-7520

56 Jones ED, Drummond TJ, Hjalmarson HP, et al. Photoluminescence studies of GaAs/AlAs short period superlattices. Superlattices MicroStruct, 1988, 4: 233-236

57 Yaffe O, Chernikov A, Norman ZM, et al. Excitons in ultrathin organic-inorganic perovskite crystals. Phys Rev B, 2015, 92: 045414

58 Kitazawa N, Aono M, Watanabe Y. Synthesis and luminescence properties of lead-halide based organic-inorganic layered perovskite compounds $\left(\mathrm{C}_{n} \mathrm{H}_{2 n+1} \mathrm{NH}_{3}\right)_{2} \mathrm{PbI}_{4}(n=4,5,7,8$ and 9). J Phys Chem Solids, 2011, 72: 1467-1471

59 Hong X, Ishihara T, Nurmikko AV. Dielectric confinement effect on excitons in $\mathrm{PbI}_{4}$-based layered semiconductors. Phys Rev B, 1992, 45: 6961-6964

60 Savenije TJ, Ponseca Jr. CS, Kunneman L, et al. Thermally activated exciton dissociation and recombination control the carrier dynamics in organometal halide perovskite. J Phys Chem Lett, 2014, 5: 2189-2194

61 Yang Y, Ostrowski DP, France RM, et al. Observation of a hotphonon bottleneck in lead-iodide perovskites. Nat Photonics, 2016, 10: 53-59

62 Chondroudis K, Mitzi DB. Electroluminescence from an organic -inorganic perovskite incorporating a quaterthiophene dye within lead halide perovskite layers. Chem Mater, 1999, 11: 30283030

63 Mitzi DB. Templating and structural engineering in organic-inorganic perovskites. J Chem Soc Dalton Trans, 2001, 1-12

64 Jeon NJ, Noh JH, Kim YC, et al. Solvent engineering for highperformance inorganic-organic hybrid perovskite solar cells. Nat Mater, 2014, 13: 897-903

65 Burschka J, Pellet N, Moon SJ, et al. Sequential deposition as a route to high-performance perovskite-sensitized solar cells. Nature, 2013, 499: 316-319

66 You J, Hong Z, Yang YM, et al. Low-temperature solution-processed perovskite solar cells with high efficiency and flexibility. ACS Nano, 2014, 8: 1674-1680

67 Liu D, Kelly TL. Perovskite solar cells with a planar heterojunction structure prepared using room-temperature solution processing techniques. Nat Photonics, 2014, 8: 133-138

68 Chen $\mathrm{Q}$, Zhou H, Hong Z, et al. Planar heterojunction perovskite solar cells via vapor-assisted solution process. J Am Chem Soc, 2013, 136: 622-625

69 Xiao M, Huang F, Huang W, et al. A fast deposition-crystallization procedure for highly efficient lead iodide perovskite thinfilm solar cells. Angew Chem, 2014, 126: 10056-10061

70 Li X, Bi D, Yi C, et al. A vacuum flash-assisted solution process for high-efficiency large-area perovskite solar cells. Science, 2016, 353: $58-62$

71 Liu M, Johnston MB, Snaith HJ. Efficient planar heterojunction perovskite solar cells by vapour deposition. Nature, 2013, 501: 395-398

$72 \mathrm{Hu} \mathrm{H}$, Wang D, Zhou Y, et al. Vapour-based processing of holeconductor-free $\mathrm{CH}_{3} \mathrm{NH}_{3} \mathrm{PbI}_{3}$ perovskite/ $\mathrm{C}_{60}$ fullerene planar solar cells. RSC Adv, 2014, 4: 28964-28967

73 Kim J, Kim G, Kim TK, et al. Efficient planar-heterojunction perovskite solar cells achieved via interfacial modification of a sol-gel ZnO electron collection layer. J Mater Chem A, 2014, 2: 17291-17296

74 Wang KC, Shen PS, Li MH, et al. Low-temperature sputtered nickel oxide compact thin film as effective electron blocking layer for mesoscopic $\mathrm{NiO} / \mathrm{CH}_{3} \mathrm{NH}_{3} \mathrm{PbI}_{3}$ perovskite heterojunction solar cells. ACS Appl Mater Interfaces, 2014, 6: 11851-11858

75 Ding X, Ren Y, Wu Y, et al. Sequential deposition method fabricating carbonbased fully-inorganic perovskite solar cells. Sci China Mater, 2018, 61: 73-79

76 Chiang $\mathrm{CH}$, Tseng ZL, Wu CG. Planar heterojunction perovskite/ $\mathrm{PC}_{71} \mathrm{BM}$ solar cells with enhanced open-circuit voltage via a (2/1)step spin-coating process. J Mater Chem A, 2014, 2: 15897-15903

77 Xiao Z, Bi C, Shao Y, et al. Efficient, high yield perovskite photovoltaic devices grown by interdiffusion of solution-processed precursor stacking layers. Energy Environ Sci, 2014, 7: 2619-2623

78 Guo Q, Li C, Qiao W, et al. The growth of a $\mathrm{CH}_{3} \mathrm{NH}_{3} \mathrm{PbI}_{3}$ thin 
film using simplified close space sublimation for efficient and large dimensional perovskite solar cells. Energy Environ Sci, 2016, 9: 1486-1494

79 Smith IC, Hoke ET, Solis-Ibarra D, et al. A layered hybrid perovskite solar-cell absorber with enhanced moisture stability. Angew Chem, 2014, 126: 11414-11417

80 Cortecchia D, Dewi HA, Yin J, et al. Lead-free $\mathrm{MA}_{2} \mathrm{CuCl}_{x} \mathrm{Br}_{4-x}$ hybrid perovskites. Inorg Chem, 2016, 55: 1044-1052

81 Liang D, Peng Y, Fu Y, et al. Color-pure violet-light-emitting diodes based on layered lead halide perovskite nanoplates. ACS Nano, 2016, 10: 6897-6904

$82 \mathrm{Li} \mathrm{Y,} \mathrm{Cooper} \mathrm{JK,} \mathrm{Liu} \mathrm{W,} \mathrm{et} \mathrm{al.} \mathrm{Defective} \mathrm{TiO}_{2}$ with high photoconductive gain for efficient and stable planar heterojunction perovskite solar cells. Nat Commun, 2016, 7: 12446

83 Wang YK, Yuan ZC, Shi GZ, et al. Dopant-free spiro-triphenylamine/fluorene as hole-transporting material for perovskite solar cells with enhanced efficiency and stability. Adv Funct Mater, 2016, 26: 1375-1381

84 Zhang F, Yi C, Wei P, et al. A novel dopant-free triphenylamine based molecular "butterfly" hole-transport material for highly efficient and stable perovskite solar cells. Adv Energy Mater, 2016, 6: 1600401

85 You J, Meng L, Song TB, et al. Improved air stability of perovskite solar cells via solution-processed metal oxide transport layers. Nat Nanotechnol, 2015, 11: 75-81

86 Ma S, Qiao W, Cheng T, et al. Optical-electrical-chemical engineering of PEDOT:PSS by incorporation of hydrophobic nafion for efficient and stable perovskite solar cells. ACS Appl Mater Interfaces, 2018, 10: 3902-3911

87 Li W, Zhang W, Van Reenen S, et al. Enhanced UV-light stability of planar heterojunction perovskite solar cells with caesium bromide interface modification. Energy Environ Sci, 2016, 9: 490-498

88 Ma Y, Deng K, Gu B, et al. Boosting efficiency and stability of perovskite solar cells with CdS inserted at $\mathrm{TiO}_{2}$ /perovskite Interface. Adv Mater Interfaces, 2016, 3: 1600729

89 Ye QQ, Wang ZK, Li M, et al. N-type doping of fullerenes for planar perovskite solar cells. ACS Energy Lett, 2018, 3: 875-882

90 Saliba M, Matsui T, Domanski K, et al. Incorporation of rubidium cations into perovskite solar cells improves photovoltaic performance. Science, 2016, 354: 206-209

91 Liao JF, Rao HS, Chen BX, et al. Dimension engineering on cesium lead iodide for efficient and stable perovskite solar cells. J Mater Chem A, 2017, 5: 2066-2072

92 Cao DH, Stoumpos CC, Yokoyama T, et al. Thin films and solar cells based on semiconducting two-dimensional ruddlesdenpopper $\left(\mathrm{CH}_{3}\left(\mathrm{CH}_{2}\right)_{3} \mathrm{NH}_{3}\right)_{2}\left(\mathrm{CH}_{3} \mathrm{NH}_{3}\right)_{n-1} \mathrm{Sn}_{n} \mathrm{I}_{3 n+1}$ Perovskites. ACS Energy Lett, 2017, 2: 982-990

93 Cohen BE, Wierzbowska M, Etgar L. High efficiency and high open circuit voltage in quasi $2 \mathrm{D}$ perovskite based solar cells. Adv Funct Mater, 2017, 27: 1604733

94 Hamaguchi R, Yoshizawa-Fujita M, Miyasaka T, et al. Formamidine and cesium-based quasi-two-dimensional perovskites as photovoltaic absorbers. Chem Commun, 2017, 53: 4366-4369

95 Yao K, Wang X, Xu Y, et al. A general fabrication procedure for efficient and stable planar perovskite solar cells: Morphological and interfacial control by in-situ-generated layered perovskite. Nano Energy, 2015, 18: 165-175

96 Wang F, Geng W, Zhou Y, et al. Phenylalkylamine passivation of organolead halide perovskites enabling high-efficiency and airstable photovoltaic cells. Adv Mater, 2016, 28: 9986-9992

97 Cho KT, Grancini G, Lee Y, et al. Selective growth of layered perovskites for stable and efficient photovoltaics. Energy Environ Sci, 2018, 11: 952-959

98 Cho H, Jeong SH, Park MH, et al. Overcoming the electroluminescence efficiency limitations of perovskite light-emitting diodes. Science, 2015, 350: 1222-1225

99 Tan ZK, Moghaddam RS, Lai ML, et al. Bright light-emitting diodes based on organometal halide perovskite. Nat Nanotechnol, 2014, 9: 687-692

100 Li G, Tan ZK, Di D, et al. Efficient light-emitting diodes based on nanocrystalline perovskite in a dielectric polymer matrix. Nano Lett, 2015, 15: 2640-2644

101 Sadhanala A, Ahmad S, Zhao B, et al. Blue-green color tunable solution processable organolead chloride-bromide mixed halide perovskites for optoelectronic applications. Nano Lett, 2015, 15: 6095-6101

102 Gong X, Yang Z, Walters G, et al. Highly efficient quantum dot near-infrared light-emitting diodes. Nat Photon, 2016, 10: 253257

103 Wang J, Wang N, Jin Y, et al. Interfacial control toward efficient and low-voltage perovskite light-emitting diodes. Adv Mater, 2015, 27: 2311-2316

104 Ling Y, Yuan Z, Tian Y, et al. Bright light-emitting diodes based on organometal halide perovskite nanoplatelets. Adv Mater, 2016, 28: 305-311

105 Xing J, Yan F, Zhao Y, et al. High-efficiency light-emitting diodes of organometal halide perovskite amorphous nanoparticles. ACS Nano, 2016, 10: 6623-6630

106 Yang X, Zhang X, Deng J, et al. Efficient green light-emitting diodes based on quasi-two-dimensional composition and phase engineered perovskite with surface passivation. Nat Commun, 2018, 9: 570

107 Mitzi DB, Chondroudis K, Kagan CR. Organic-inorganic electronics. IBM J Res Dev, 2001, 45: 29-45

108 Gauthron K, Lauret JS, Doyennette L, et al. Optical spectroscopy of two-dimensional layered $\left(\mathrm{C}_{6} \mathrm{H}_{5} \mathrm{C}_{2} \mathrm{H}_{4} \mathrm{NH}_{3}\right)_{2}-\mathrm{PbI}_{4}$ perovskite. Opt Express, 2010, 18: 5912-5919

109 Era M, Morimoto S, Tsutsui T, et al. Organic-inorganic heterostructure electroluminescent device using a layered perovskite semiconductor $\left(\mathrm{C}_{6} \mathrm{H}_{5} \mathrm{C}_{2} \mathrm{H}_{4} \mathrm{NH}_{3}\right)_{2} \mathrm{PbI}_{4}$. Appl Phys Lett, 1994, 65: 676-678

Acknowledgements This work is supported by the National Key Research and Development Program of China (2016YFA0202401), the 111 Project (B16016), the National Natural Science Foundation of China (51572080, 51702096 and U1705256), and the Fundamental Research Funds for the Central Universities (2017XS080).

Author contributions Ma S investigated the relevant literature and wrote this manuscript. Cai $M$ and Cheng T helped the logical framework of this manuscript. Dai S, Ding Y and Tan Z carefully reviewed and modified this manuscript. Ding X, Shi X, Alsaedi A and Hayat T gave some valuable suggestions on revision. All authors contributed to the general discussion about this work.

Conflict of interest The authors declare no competing interests. 

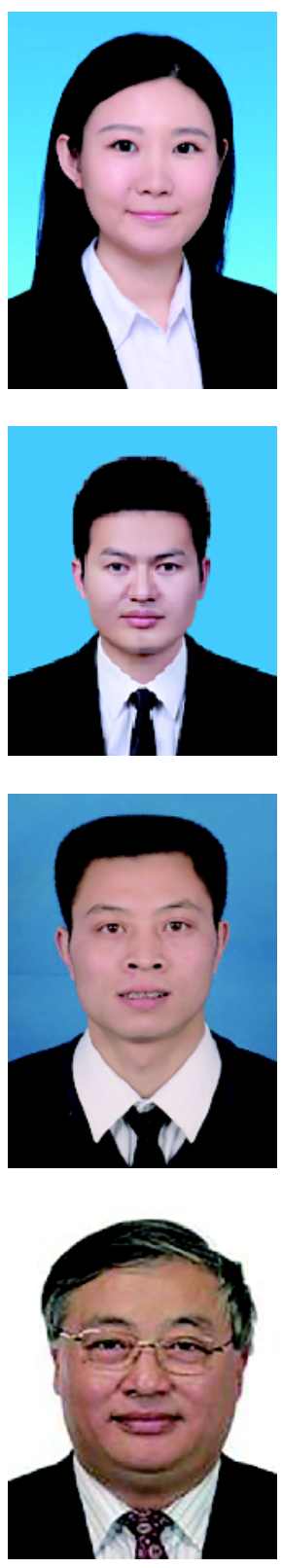

Shuang Ma obtained her BSc degree from North China Electric Power University in 2015. She is a PhD candidate of the North China Electric Power University under the supervision of Prof. Yong Ding and Prof. Songyuan Dai. Her research interest is perovskite solar cells.
Yong Ding is a lecturer in Beijing Key Lab of Novel Thin Film Solar Cells, North China Electric Power University. He received his PhD in physical chemistry from Hefei Institutes of Physical Science, Chinese Academy of Sciences in 2011. His research interest is novel-type solar cells, including dye-sensitized solar cells and perovskite solar cells.

Zhan'ao Tan is a full professor in Beijing Key Laboratory of Novel Thin Film Solar Cells, North China Electric Power University, since 2009, and currently leads the Group of Organic Optoelectronic Materials and Devices. He received his $\mathrm{PhD}$ degree in physical chemistry in 2007 from the Institute of Chemistry, Chinese Academy of Sciences and then came to Pennsylvania State University, USA, as a postdoctoral fellow working on semiconductor quantum dots based lightemitting diodes and photovoltaics from 2007 to 2009. His present research interest includes polymer solar cells, semiconductor nanocrystal based optoelectronics, organic-inorganic hybrid perovskite solar cells, and flow batteries.

Songyuan Dai is a Professor and Dean of Renewable Energy School, North China Electric Power University. He received his BS from Department of Physics, Anhui Normal University in 1987, and his MSc and PhD degrees from Institute of Plasma Physics, Chinese Academy of Sciences, in 1991, and 2001, respectively. His current research interests include dyesensitized solar cell, perovskite solar cells, quantum dot solar cells and nanomaterials.

\section{二维有机-无机杂化钲钛矿: 从材料性能到器件应用}

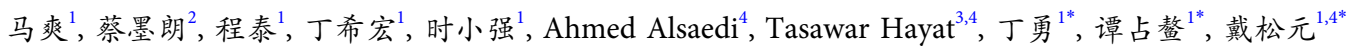

摘要 二维 $(2 \mathrm{D})$ 钙钛矿材料(包括纯 $2 \mathrm{D}$ 和准 $2 \mathrm{D}$ ) 是在传统意义上的三维钙钛矿晶格中插入大基团卤化铵形成的. 在过去的 20 年里, 二维钲 钛矿材料种类不断丰富, 相关理论研究不断深入, 在光电器件领域的应用不断拓展. 本综述介绍了 $2 \mathrm{D}$ 钲钛矿材料的基本形成机制和性能, 汇总和比较了 $2 \mathrm{D}$ 钲钛矿薄膜的制备方法, 并给出了其在太阳电池以及发光二极管领域的应用实例. 最后, 提出了该领域亟待解决的问题, 以及未来的研究趋势. 